\title{
Modelling of underwater light fields in turbid and eutrophic waters: application and validation with experimental data
}

\author{
B. Sundarabalan and P. Shanmugam \\ Ocean Optics and Imaging Laboratory, Department of Ocean Engineering, Indian Institute of Technology Madras, \\ Chennai-600036, India \\ Correspondence to: P. Shanmugam (pshanmugam@iitm.ac.in)
}

Received: 18 August 2014 - Published in Ocean Sci. Discuss.: 15 September 2014

Revised: 17 November 2014 - Accepted: 2 December 2014 - Published: 9 January 2015

\begin{abstract}
A reliable radiative transfer (RT) model is an essential and indispensable tool for understanding the radiative transfer processes in homogenous and layered waters, analyzing measurements made by radiance sensors and developing remote-sensing algorithms to derive meaningful physical quantities and biogeochemical variables in turbid and productive coastal waters. Existing radiative transfer models have been designed to be applicable to either homogenous waters or inhomogeneous waters. To overcome such constraints associated with these models, this study presents a radiative transfer model that treats a homogenous layer as a diffuse part and an inhomogeneous layer as a direct part in the water column and combines these two parts appropriately in order to generate more reliable underwater lightfield data such as upwelling radiance $\left(L_{\mathrm{u}}\right)$, downwelling irradiance $\left(E_{\mathrm{d}}\right)$ and upwelling irradiance $\left(E_{\mathrm{u}}\right)$. The diffuse model assumes the inherent optical properties (IOPs) to be vertically continuous and the light fields to exponentially decrease with depth, whereas the direct part considers the water column to be vertically inhomogeneous (layer-by-layer phenomena) with the vertically varying phase function. The surface and bottom boundary conditions, source function due to chlorophyll and solar incident geometry are also included in the present RT model. The performance of this model is assessed in a variety of waters (clear, turbid and eutrophic) using the measured radiometric data. The present model shows an advantage in terms of producing accurate $L_{\mathrm{u}}, E_{\mathrm{d}}$ and $E_{\mathrm{u}}$ profiles (in spatial domain) in different waters determined by both homogenous and inhomogeneous conditions. The feasibility of predicting these underwater light fields based on the remotely estimated IOP data is also examined using the present RT model. For this application, vertical profiles of
\end{abstract}

the water constituents and IOPs are estimated by empirical models based on our in situ data. The present RT model generates $L_{\mathrm{u}}, E_{\mathrm{d}}$ and $E_{\mathrm{u}}$ spectra closely consistent with the measured data. These results lead to a conclusion that the present RT model is a viable alternative to existing RT models and has an important implication for remote sensing of optically complex waters.

\section{Introduction}

Knowledge of the transmission and distribution of light fields within the water body is essential for the solution of many problems in optical remote sensing, underwater visibility, underwater imaging, underwater communication and naval operations. In the past decades, several radiative transfer (RT) models have been developed to compute the reflectance and transmittance of direct and diffuse solar fluxes at the ocean surface and in the water column. For instance, Kirk (1981) presented the Monte Carlo simulation scheme for studying the radiative transfer processes in the ocean and other natural waters. Stamnes et al. (1988) summarised an advanced and thoroughly documented discrete ordinate method (DISORT) for time-independent radiative transfer calculations in vertically inhomogeneous, non-isothermal, plane-parallel media. Mobley (1994) developed the HydroLight software, which is a radiative transfer numerical model based on the invariant imbedding technique that computes spectral radiance distributions within and leaving the natural water bodies. Haltrin developed a method for estimating the underwater light-field parameters in the homogeneous water column illuminated by the direct sun light and sky light (Haltrin and Kattawar, 
1993; Haltrin, 1998a, b). Lee and Liou (2007) developed a radiative transfer model for a coupled atmosphere-ocean system using the analytic four-stream approximation. Hollstein and Fischer (2012) provided radiative transfer solutions for coupled atmosphere-ocean systems using the matrix operator technique. These RT models developed based on numerical as well as analytical solutions perform well in clear oceanic waters but have limitations in turbid coastal and productive waters. The key problems associated with some of the above models include the assumption of flat or randomly chosen slope of the sea surface, the treatment of material reflectance instead of the effective bottom reflectance (taking into account the material reflectance and configuration of the seabed), the constant phase function along the depth and the inadequate source function (especially for turbid and productive waters often optically shallow, vertically stratified, or vertically mixed) which introduce significant errors in the simulated underwater light fields (Sundarabalan et al., 2013). Conversely, the radiative transfer models developed for a inhomogeneous medium do not account for diffuse radiance in the water column, where the influence of inherent optical properties (IOPs) from a particular (adjacent) layer is not the only factor affecting underwater light fields in that layer but the subsequent layers (with non-uniform IOPs) would have potential contributions to modifying the underwater lightfield environment. Moreover, the assumption of the homogenous water column in some of the RT models is not valid in many coastal waters where the water constituents would vary with depth (e.g. an increasing trend of turbidity with depth in many coastal regions). Thus, a reliable RT model is needed accounting for the vertically varying IOPs and treating the surface and bottom boundary conditions adequately in order to provide accurate underwater light-field data in turbid coastal waters.

Ocean colour data provided by modern day sensors (e.g. NASA's SeaWiFS on board its SeaStar satellite and MODIS on board its Aqua satellite, ESA's MERIS on board its Envisat satellite, Ocean Colour Monitor (OCM) from the Indian Space Research Organisation (ISRO) on board its Indian Remote Sensing (IRS) satellite and more recently Geostationary Ocean Colour Imager (GOCI) from the Korea Aerospace Research Institute (KARI) onboard its Communication, Ocean and Meteorological Satellite (COMS) satellite) are a vital resource for a wide variety of operational forecasting and oceanographic research, and related applications. With the advent of these new sensors, the prospects of better algorithms to enable the interpretation of ocean colour in coastal oceanic waters have improved vastly. Some of the potential applications of these sensors include monitoring and assessment of the spatial and temporal variability of algal blooms (instrumental in characterising variability of marine ecosystems and is a key tool for research into how marine ecosystems respond to climate change and anthropogenic perturbations), coastal marine pollution, river plumes, global carbon budgets, ocean radiant heat budgets and climate change im- pacts. Many of these applications can be achieved by estimating IOPs from the remote-sensing data, since light transmission in the water column is determined by these properties that depend mainly on the contents of chlorophyll (Chl), suspended sediments (SS) and coloured dissolved organic matter (CDOM). In most oceanic waters IOPs are determined primarily by phytoplankton and its associated detrital matter, which in turn determine the distribution and spectral quality of the underwater light fields (Morel, 1988; Hoepffner and Sathyendranath, 1992). Though several inversion models have been developed to estimate IOPs from remote-sensing data, they are often reported to yield large uncertainties in turbid coastal waters. Similar problems also exist with the retrieval of the water constituents' concentrations from satellite observations in these waters (O'Reilly et al., 1998; O'Reilly et al., 2000; Shanmugam, 2011a). The errors of more than $10 \%$ in retrieval of IOPs (Stramski, 2001) and even much higher (20 times higher than measurements) in retrieval of chlorophyll are reported (Wozniak and Stramski, 2004).

The surface chlorophyll concentration estimated from satellite ocean colour data is used as an important parameter for reconstruction of its vertical profile in the water column (Morel, 1988; Platt and Sathyendranath, 1988; Sathyendranath and Platt, 1988; Morel and Berthon, 1989; Antoine et al., 1996; Uitz et al., 2006). The generalised Gaussian profile (Lewis et al., 1983) is used to predict the average dimensionless chlorophyll profile, superimposed onto a constant background concentration. The shape of the chlorophyll profiles directly depends on the subsurface chlorophyll maximum (SCM) $[\mathrm{Chl}]_{\max }$ and depth of chlorophyll maximum (DCM) $Z_{\max }$ which are parameterised using the surface chlorophyll data. While the background is generally considered as the surface chlorophyll concentration, some of the existing models assume it to decrease progressively with depth (Martin et al., 2010; Stramska and Stramski, 2005; Arrigo et al., 2011; Cherkasheva et al., 2013). Previously, Morel and Berthon (1989) modelled Chl profile shapes for nine tropic categories and developed a global algorithm for SCM, DCM and other parameters, regardless of region and season. The estimation of these profile parameters from the existing algorithms is applicable for certain seasons and regions. After the comprehensive study of DCM (Martin et al., 2010), it is confirmed that the published global, statistical relationships between the surface $\mathrm{Chl}$ and profile parameters lead to a severe underestimation when the SCM is sharp and intense in clear oceanic waters. This investigation motivates us to determine the new relation between the surface $\mathrm{Chl}$ versus profile parameters for predicting the column integrated chlorophyll profiles. In coastal waters, suspended sediments also play a major role in the determination of underwater light fields. Like the chlorophyll profiles, the surface suspended sediment concentration is used to extrapolate the SS along the depth. Previously, Ramakrishnan et al. (2013) used the power-law function to predict the vertical SS profiles from OCM data. 
It is well known that the underwater radiometric parameters directly depend on IOPs of the water body (Shanmugam et al., 2010, 2011). The IOPs are mainly absorption $(a)$, attenuation $(c)$, scattering $(b)$ and backscattering $\left(b_{\mathrm{b}}\right)$ coefficients which are generally derived as a function of the chlorophyll concentration in oceanic waters. Over the past decades, several models have been developed to estimate IOPs in case 1 waters (Prieur and Sathyendranath, 1981; Ahn, 1990; Bricaud et al., 1995; Babin et al., 2003; Matsuoka et al., 2011). However, the overly simplified parameterisations do not account for much of the optical variability observed in natural waters, leading to large uncertainties in case 2 waters (Babin et al., 2003; Dmitriev et al., 2009). The variations in these parameters can be attributed to three water constituents, such as phytoplankton, yellow substances (CDOM) and nonalgal particles (both organic and inorganic). The particulate absorption $\left(a_{\mathrm{p}}\right)$ is mainly dominated by the non-algal particles, but phytoplankton becomes the dominant contributor in algal bloom waters (Wang et al., 2011). Stramski et al. (2001) explain that the mineral particles could be important for scattering and backscattering. Recently, Gokul et al. (2014) have developed models to predict IOPs and their vertical profiles using the remote-sensing reflectance data.

This work intends to derive a generalised radiative transfer model for predicting the underwater light fields in a variety of waters (including turbid coastal waters and eutrophic waters). The model is run with the in situ IOP data and predicted IOP data from remote-sensing data and its results are compared with the measured radiometric data. The results of the present RT model are further discussed for a variety of waters around southern India.

\section{Data and methods}

In situ measurements of the various optical and physical properties together with the water sampling were conducted in relatively clear and turbid coastal waters off Point Calimere, Chennai and eutrophic (lagoon) waters around Chennai during August 2012 and August, November and December 2013. The nature and characteristics of these waters have been investigated in a recent study by Pravin and Shanmugam (2014). For each station, water samples were collected from discrete depths and filtered and analysed for the determination of Chl, SS and CDOM contents (Gokul et al., 2014). Table 1 summarises some important symbols and notations used in this paper. The data used for this study and the sampling stations are described in Table 2. The vertical profiles of IOPs and other properties were measured with WETLabs AC-S, BB9 and FLNTU sensors. Necessary corrections (for temperature, salinity and scattering effects) were applied to the AC-S data to obtain more reliable absorption and attenuation data (Pegau et al., 1997). Physical properties of the seawater such as conductivity, temperature and depth were measured by a SBE-CTD sensor to support the above data processing and analysis.

Field radiometric measurements were carried out using RAMSES (TriOS) hyperspectral radiometers; RAMSES ARC and ACC were used to measure the upwelling radiance $\left(L_{\mathrm{u}}\right)$, upwelling irradiance $\left(E_{\mathrm{u}}\right)$ and downwelling irradiance $\left(E_{\mathrm{d}}\right)$ in the water column. The irradiance sensor has an inbuilt pressure sensor which provides the corresponding depth in the water column. Both these sensors measure the radiance signal in the visible and near-infrared $(0.350$ $0.950 \mu \mathrm{m})$ with a field of view of $7^{\circ}$ and spectral accuracy of $0.0033 \mu \mathrm{m}$. Since the radiance sensor was immersed in water, the immersion factors (wavelength-dependent correction factors) were used to correct the measured radiance signal (Pravin and Shanmugam, 2014). Similarly, the above-surface measurements were made with another set of TriOS sensors that provided the sky radiance $L_{\mathrm{sky}}$, downwelling irradiance $E_{\mathrm{d}}\left(0^{+}\right)$and total radiance $L_{\mathrm{t}}$. The desired water-leaving radiances were determined after eliminating the surface-reflected light contributions to the total radiance signal (Pravin and Shanmugam, 2014).

\section{Modelling}

Figure 1 shows the schematic flow diagram of the present RT model. It can simulate the underwater light fields based on the measured IOPs (right part) or predicted IOPs from the remote-sensing data (left part) for the same solar incident geometry and surface and bottom boundary conditions. For the second part, surface $\mathrm{Chl}$ and SS are estimated from remotesensing reflectance data and their vertical profiles are subsequently predicted using the known functions. These vertical profiles are used to derive the IOPs (hereafter referred to as Pred IOP). Finally, the Pred IOPs are used along with the other input parameters to simulate the underwater light fields. The step-by-step procedure is detailed in what follows.

\subsection{Radiative transfer model}

Radiative transfer is the physical phenomenon of energy transfer in the form of electromagnetic radiation. The propagation of radiation through a medium is affected by absorption, emission and scattering processes. The equation of radiative transfer describes these interactions mathematically. The basic RT equation that connects the radiance and IOPs is expressed as follows:

$$
\begin{aligned}
\cos \theta \frac{\mathrm{d} L(z, \theta, \phi, \lambda)}{\mathrm{d} z} & =-c(z, \lambda) L(z, \theta, \phi, \lambda) \\
& +\int_{4 \pi} L\left(z, \theta^{\prime}, \phi^{\prime}, \lambda\right) \\
& \times \beta\left(z ; \theta^{\prime}, \phi^{\prime} \rightarrow \theta, \phi ; \lambda\right) \mathrm{d} \Omega^{\prime} \\
& +S(z, \theta, \phi, \lambda) .
\end{aligned}
$$




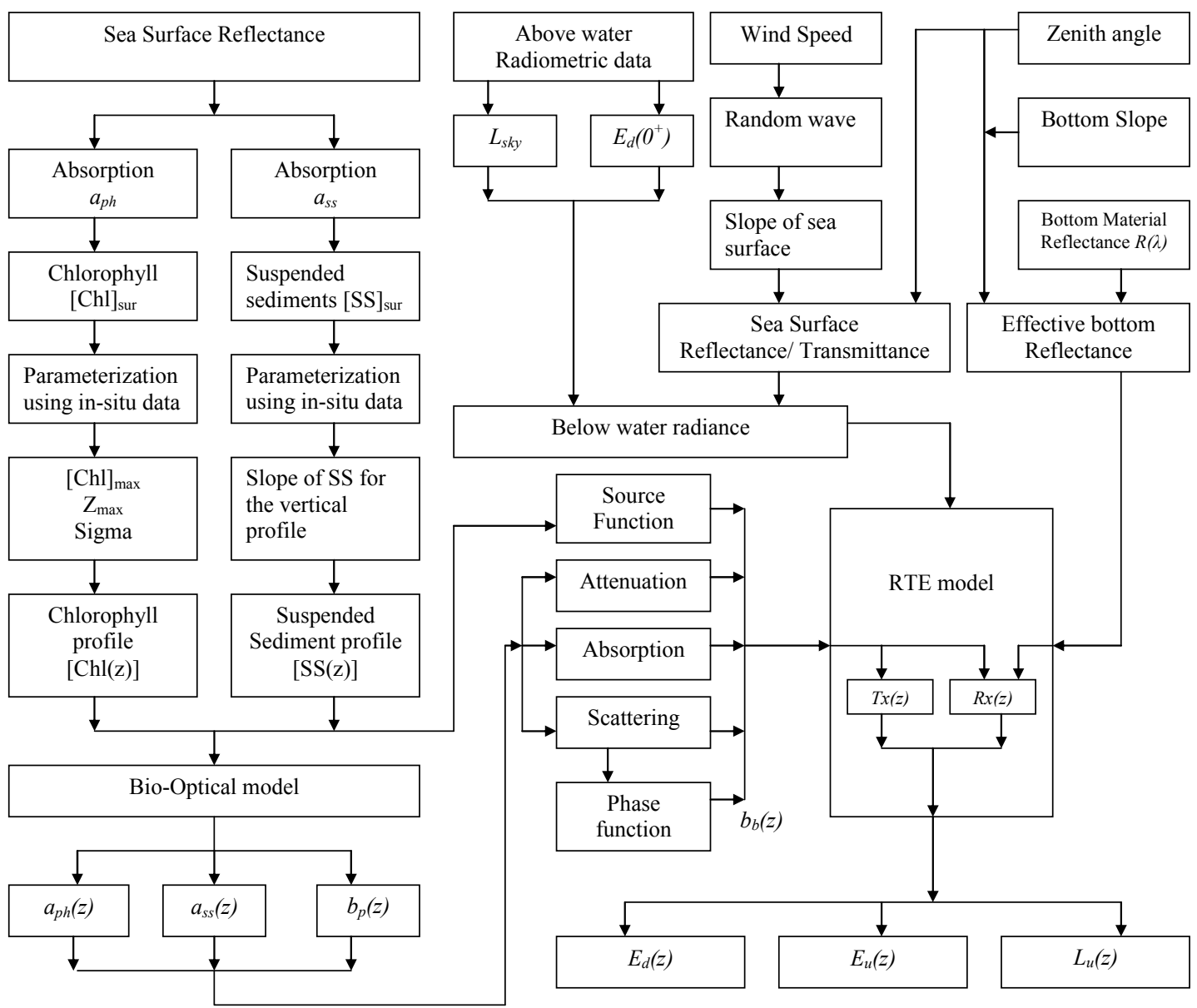

Figure 1. The schematic block diagram indicates the overall system for the simulation of underwater light fields using the present RT model with the in situ IOP (right) or predicted IOP from remote-sensing data (left) along with other input parameters.

The scattering angle $\psi$ in the volume scattering function (VSF) is the angle between the incident direction $\left(\theta \prime, \varphi^{\prime}\right)$ and the scattered direction $(\theta, \varphi)$. The source term $S(z, \theta, \varphi, \lambda)$ describes either an internal light source such as bioluminescence or inelastically scattered light from other wavelengths.

Figure 2 shows the schematic representation of the inwater radiative transfer technique for homogenous and inhomogeneous waters with the direct and diffuse terms. For practical applications, it is important to consider the influences of homogenous (diffuse term) and inhomogeneous (direct term) layers of the water column on the underwater lightfield parameters. The homogenous and inhomogeneous effects are included in the present RT model (by taking the average of these two terms) to simulate the underwater light fields in a wide variety of waters (including relatively clear, turbid and eutrophic waters). The downwelling irradiances along the depth for both homogenous $\left(\mathrm{HE}_{\mathrm{d}}\right)$ and inhomogeneous waters $\left(E_{\mathrm{d}}\right)$ can be calculated using

$E_{\mathrm{d}}(z)=\left(\frac{1}{2}\right)\left(\mathrm{HE}_{\mathrm{d}}(z)+E_{\mathrm{d}}(z)\right)$.

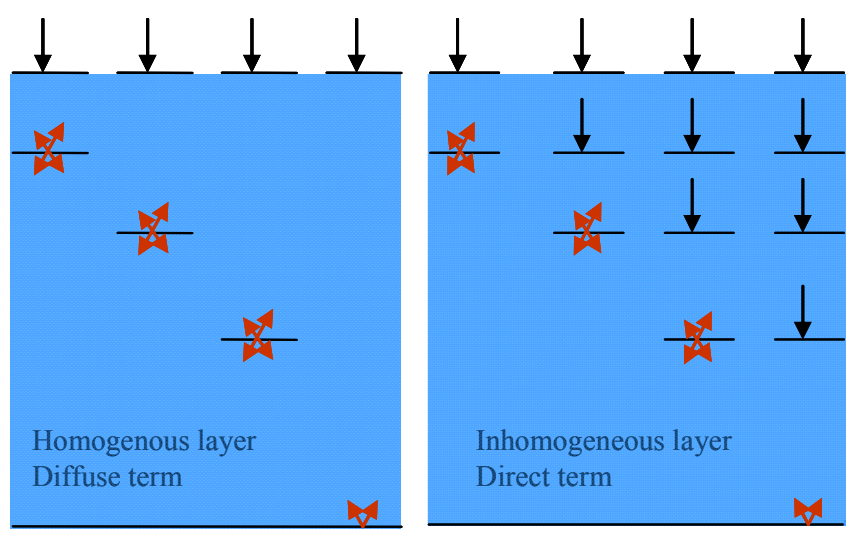

Figure 2. Schematic diagram showing the homogenous (left) and inhomogeneous radiative transfer concepts (right) with the diffuse and direct terms for the layers in the water column from the sea surface to sea bed. 
Table 1. Symbols and notations.

\begin{tabular}{lll}
\hline Symbol & Description & Unit \\
\hline$U$ & Wind speed & $\mathrm{m} \mathrm{s}^{-1}$ \\
$\theta_{z}$ & Solar zenith angle & degree \\
$z$ & Depth & $\mathrm{m}$ \\
$n_{\mathrm{W}}$ & Refractive index & \\
$\mu$ & Average cosine & \\
$q$ & Transmittance at air-water interface & \\
$\mathrm{Tx}_{\mathrm{F}}$ & Fresnel transmittance at air-water interface & \\
$\mathrm{Rf}_{\mathrm{F}}$ & Fresnel reflectance at air-water interface & \\
$T(z)$ & Transmittance at depth z & \\
$R(z)$ & Reflectance at depth z & \\
$R_{\mathrm{S}}$ & Diffuse reflectance (direct solar light) & \\
$R_{\infty}$ & Diffuse reflectance (diffuse light) & \\
$c$ & Attenuation & $\mathrm{m}^{-1}$ \\
$a$ & Absorption & $\mathrm{m}^{-1}$ \\
$b$ & Scattering & $\mathrm{m}^{-1}$ \\
$E_{\mathrm{d}}\left(0^{+}\right)$ & Downwelling irradiance just above the water & $\mathrm{mW} \mathrm{cm}^{2} \mu \mathrm{m}^{-1}$ \\
$E_{\mathrm{d}}\left(0^{-}\right)$ & Downwelling irradiance just below the water & $\mathrm{mW} \mathrm{cm}^{2} \mu \mathrm{m}^{-1}$ \\
$E_{\mathrm{d}}(z)$ & Downwelling irradiance & $\mathrm{mW} \mathrm{cm}^{2} \mu \mathrm{m}^{-1}$ \\
$E_{\mathrm{u}}(z)$ & Upwelling irradiance & $\mathrm{mW} \mathrm{cm}^{2} \mu \mathrm{m}^{-1}$ \\
$L_{\mathrm{u}}(z)$ & Upwelling radiance & $\mathrm{mW} \mathrm{cm}^{2} \mu \mathrm{m}^{-1} \mathrm{sr}^{-1}$ \\
{$[\mathrm{Chl}]_{\text {sur }}$} & Surface chlorophyll concentration & $\mathrm{mg} \mathrm{m}^{-3}$ \\
{$[\mathrm{SS}]_{\mathrm{sur}}$} & Surface suspended sediments concentration & $\mathrm{mg} \mathrm{m}^{-3}$ \\
$Z_{\mathrm{max}}$ & Depth of chlorophyll maximum & $\mathrm{m}^{-3}$ \\
{$[C h \mathrm{Ch}]_{\mathrm{max}}$} & Subsurface chlorophyll maximum & $\mathrm{mg} \mathrm{m}^{-3}$ \\
$\sigma$ & Standard deviation & $\mathrm{m}$ \\
\hline
\end{tabular}

From the downwelling irradiance and reflectance at different depths, the upwelling irradiance (for both homogenous, $\mathrm{HE}_{\mathrm{u}}$, and inhomogeneous, $E_{\mathrm{u}}$ ) can be calculated from

$E_{\mathrm{u}}(z)=\left(\frac{1}{2}\right)\left[\mathrm{HE}_{\mathrm{u}}(z)+E_{\mathrm{u}}(z)\right]+\left[\frac{S(z)}{4 \pi}\right]$

These equations provide more accurate upwelling irradiances along the depth. The upwelling radiance along the depth (for homogenous and inhomogeneous) can be calculated from

$L_{\mathrm{u}}(z)=\left[\frac{E_{\mathrm{u}}(z)}{2 \pi \mu}\right]$

Using the above equations one can generate the underwater light fields and study their fluctuations in both clear and turbid waters. The inhomogeneous or direct term includes the phase function, source term and surface and bottom boundary conditions which are solved in equal interval along the water column. The homogeneous term or diffuse term is directly calculated from the IOPs for any arbitrary depth (Haltrin, 1998b).

\subsubsection{Boundary conditions}

\section{Surface transmittance}

The propagation of light through the sea surface is calculated from the reflected and transmitted angles using the Fresnel function (Gjerstad et al., 2003). Since the resulting underwater light fields strongly depend on the exact shape of the wave, the slope of the sea surface plays an important role in determining the transmitted and reflected angles. In this study, the shape of the irregular sea surface is generated based on the wind speed using the Pierson and Moskowitz (PM) spectrum (Pierson and Moskowitz, 1964) which is obtained from the field data. The slope is calculated based on the generated irregular sea surface. From this slope, the tilt angle is calculated based on Snell's law. The equation used to determine the tilt angle $(\gamma)$ of the sea surface from the slope is expressed as follows:

$\gamma=\tan ^{-1}\left[\frac{\Delta z}{\Delta x}\right]$

where $\Delta x$ and $\Delta z$ are the differential space of sea surface waves in the horizontal and vertical directions, respectively. Snell's law for the flat surface is given by $n_{1} \sin \left(\theta_{i}\right)=$ $n_{2} \sin \left(\theta_{\mathrm{t}}\right)$, where $\theta_{i}$ and $\theta_{\mathrm{t}}$ are the incident and transmitted angles and $n$ is the refractive index. After including the slope of 
the titled angle in the above equation, the transmitted angle for the sea surface is calculated from

$\theta_{\mathrm{t}}=\sin ^{-1}\left[\frac{n_{1}}{n_{2}} \sin \left(\theta_{i}+\gamma\right)\right]-\gamma$.

The modified transmitted and incident angles are applied in the Fresnel equation as follows:

$$
\begin{aligned}
\operatorname{Rf}_{\mathrm{F}} & =\frac{1}{2}\left[\left(\frac{\sin \left(\theta_{i}-\theta_{\mathrm{t}}\right)}{\sin \left(\theta_{i}+\theta_{\mathrm{t}}\right)}\right)^{2}+\left(\frac{\tan \left(\theta_{i}-\theta_{\mathrm{t}}\right)}{\tan \left(\theta_{i}+\theta_{\mathrm{t}}\right)}\right)^{2}\right], \quad \theta_{i} \neq \theta_{\mathrm{t}} \\
& =\left(\frac{n_{\mathrm{w}}-1}{n_{\mathrm{w}}+1}\right)^{2}, \quad \theta_{i}=\theta_{\mathrm{t}} \\
\operatorname{Tx}_{\mathrm{F}} & =1-\mathrm{Rf}_{\mathrm{F}} .
\end{aligned}
$$

The transmittance calculated from the above equation is used as the interface between the air and water for the downwelling irradiance (notations given in Table 1).

\section{Bottom reflectance}

The effective reflectance $R_{\text {eff }}$ of the bottom (considering the bottom material and morphology) is calculated according to Zaneveld and Boss (2003):

$$
\frac{R_{\mathrm{eff}}(\lambda)}{R_{\mathrm{b}}(\lambda)}=0.5 \times \cos \left[\theta_{z}+\theta_{\mathrm{b}}\right]+0.5 \times \cos \left[\theta_{z}-\theta_{\mathrm{b}}\right],
$$

where $\theta_{\mathrm{b}}=a \tan \left(4 A_{\mathrm{b}} / L_{\mathrm{b}}\right)$ the angle of the bottom slope (due to ripples on the sea bed), and $\theta_{z}$ is the zenith angle of the irradiance. $A_{\mathrm{b}}$ and $L_{\mathrm{b}}$ are the amplitude and wavelength, respectively, for the triangular shaped bottom. The effective reflectance spectra of the sea bottom are not same for different materials since the reflectance is about to vary for different materials.

\subsubsection{Optical properties in the water column}

\section{Phase function}

The angular distributions of scattered radiance are mainly explained in terms of the phase function, which plays an important role in coastal waters. The characteristic of phase functions in natural volumetric media is sharply peaked in the forward scattering direction, with only a few percent of backscatter in the total angular redistribution of a single scattering event (Sundarabalan et al., 2013). Of several phase function models developed in the past, the Fournier-Forand (FF) model is an analytic form of the phase function giving better results when compared to other models (Mobley et al., 2002). The FF phase function is given by

$$
\begin{aligned}
\beta(\theta)= & \frac{1}{4 \pi(1-\delta)^{2} \delta^{v}}\left\{\left[v(1-\delta)-\left(1-\delta^{v}\right)\right]\right. \\
& \left.+\left[\delta\left(1-\delta^{v}\right)-v(1-\delta) \sin ^{-2}\left(\frac{\theta}{2}\right)\right]\right\}
\end{aligned}
$$

$$
\begin{gathered}
+\frac{1-\delta_{180}^{v}}{16 \pi\left(\delta_{180}-1\right) \delta_{180}^{v}}\left(3 \cos ^{2} \theta-1\right) \\
v=\frac{3-\mu}{2}, \quad \delta=\frac{4}{3(n-1)^{2}} \sin ^{2}\left(\frac{\theta}{2}\right) .
\end{gathered}
$$

Here $\mu$ is the slope of the Junge particle distribution, $n$ is the real index of refraction and $\delta_{180}$ is calculated by considering $\theta=180^{\circ}$. Based on previous studies (Twardowski et al., 2001; Freda and Piskozub, 2007; Sundarabalan et al., 2013), the parameters $\mu$ and $n$ are modelled using the IOPs, attenuation $c(520)$ and scattering $b(520)$. Finally, the backscattering $b_{\mathrm{b}}$ coefficients are computed from the phase function for scattering angles between 90 and $180^{\circ}$,

$$
b_{\mathrm{b}}(520)=\int_{\frac{\pi}{2}}^{\pi} \beta(\theta) d \theta
$$

The spectral variation of the backscattering $b_{\mathrm{b}}$ coefficients can be expressed as (Haltrin, 2002)

$b_{\mathrm{b}}(\lambda)=b_{\mathrm{b}}(520) \times\left(\frac{520}{\lambda}\right)^{1.1}$.

This phase function is mainly used to determine the $b_{\mathrm{b}}$ coefficients along the depth, which are more compatible for turbid coastal waters.

\section{Transmittance along the depth}

Haltrin (1998b) derived the transmittance as a function of depth $T(z)$ based on the self-consistent method, which depends on the IOPs of seawater. The transmittance function $T(z)$ is expressed as

$$
T(z)=\frac{1+q\left\{\mu_{\mathrm{s}} \varepsilon(z)+h R_{\mathrm{S}} F_{\mathrm{S}}(z)\left[(2+\bar{\mu}) \mu_{\mathrm{s}}+1\right]\right\}}{1+q \mu_{\mathrm{S}}} .
$$

Several important parameters that depend on the IOPs are used to calculate $T(z) . \mu_{\mathrm{S}}$ is the cosine function related to the solar angle which is calculated based on the refractive index of seawater $(n)$ and the solar elevation $h_{\mathrm{s}} . \bar{\mu}$ is the average cosine that connects with Gordon's parameter $g$, which depends on the absorption and backscattering coefficients. The result obtained by solving the RT equation is $\alpha_{\infty}$ which is found by dividing absorption ( $a$ ) by the average cosine $(\bar{\mu})$. $\mu_{0}$ is another cosine function which depends on the average cosine $\bar{\mu}$. The reflectance parameters involved in the calculation of $T(z)$ are the diffuse reflectance $\left(R_{\mathrm{S}}\right)$ of a deep sea layer optically illuminated by direct solar light and the diffuse reflectance $\left(R_{\infty}\right)$ of the optically deep sea illuminated by the diffuse light. Both are calculated as a function of the cosine functions as follows:

$$
R_{\mathrm{S}}=\frac{(1-\bar{\mu})^{2}}{1+\bar{\mu} \mu_{\mathrm{S}}\left(4-\bar{\mu}^{2}\right)}, \quad R_{\infty}=\left(\frac{1-\bar{\mu}}{1+\bar{\mu}}\right)^{2} .
$$


The average cosine function used in the above equation is defined as

$\bar{\mu}=\left\{\frac{1-g}{1+2 g+[g(4+5 g)]^{1 / 2}}\right\}^{1 / 2}$,

$\mu_{0}=\frac{1+\bar{\mu}^{2}}{\bar{\mu}\left(3-\bar{\mu}^{2}\right)}$,

$\mu_{\mathrm{s}}=\left[1-\left(\frac{\cosh _{\mathrm{s}}}{n_{\mathrm{w}}}\right)^{2}\right]^{1 / 2}$,

where $c=a+b$ is the beam attenuation coefficient, $q=\frac{E_{\mathrm{s}}^{\perp}}{E_{\mathrm{d}}^{0}}$ is the transmittance at air-sea interface, $\alpha=a+2 b_{\mathrm{b}}$ is the re-normalised attenuation coefficient, $\alpha_{\infty}=\frac{a}{\bar{\mu}}$ is the intermediate parameter which depends on IOPs and $g=\frac{b_{\mathrm{b}}}{a+b_{\mathrm{b}}}$ is the Gordon's parameter (Gordon et al., 1975; Haltrin, 2003) which depends on absorption and scattering.

The IOP-dependent intermediate parameters are defined as

$\varepsilon(z)=\exp \left[-\alpha z\left(\frac{1}{\mu_{\mathrm{s}}}-\frac{1}{\mu_{0}}\right)\right], \quad h=\frac{(1+\bar{\mu})^{2}}{2\left(1+\bar{\mu}^{2}\right)}$,

$F_{\mathrm{s}}(z)=\left(1-\exp \left[-\alpha z\left(\frac{1}{\mu_{\mathrm{s}}}-\frac{1}{\mu_{0}}\right)\right]\right) /\left(\frac{1}{\mu_{\mathrm{s}}}-\frac{1}{\mu_{0}}\right)$,

$\mu_{\mathrm{s}} \neq \mu_{0}$,

$F_{\mathrm{S}}(z)=\alpha z, \quad \mu_{\mathrm{s}}=\mu_{0}$.

The above parameters, $\varepsilon(z), h$, and $F_{\mathrm{S}}(z)$, are the functions calculated based on the IOPs and solar elevation (Haltrin, 1998b).

\section{Reflectance along the depth}

The reflectance along the depth $R(z)$ is generally calculated based on the IOPs $\left(b_{\mathrm{b}} /\left(a+b_{\mathrm{b}}\right)\right)$, but it is also highly influenced by the bottom material and solar zenith angle (Lee et al., 1998, 1999). Thus, the reflectance along the depth is calculated from Lee et al. (1998), which takes into account the bottom material effect and the IOPs of the water column. The model parameters are defined as follows:

$R(z)=R_{\mathrm{iop}}(z)+R_{\mathrm{btm}}(z)$.

The reflectance influenced by the IOPs and bottom effect are calculated from the following equations:

$R_{\text {iop }}(z)=$

$r_{\mathrm{rs}}(z) \times\left\{1-\exp \left[-\kappa(z) H\left(D_{\mathrm{u}}^{\mathrm{c}}+\left(\frac{1}{\cos \theta_{\mathrm{w}}}\right)\right)\right]\right\}$,

$R_{\mathrm{btm}}(z)=$

$R_{\text {effbtm }} \times\left\{-\exp \left[-\kappa(z) H\left(D_{\mathrm{u}}^{\mathrm{b}}(z)+\left(\frac{1}{\cos \theta_{\mathrm{w}}}\right)\right)\right]\right\}$,

where $D_{\mathrm{u}}^{\mathrm{c}}$ is the path-elongation factor for scattered photons from the water column which varies with the IOPs. The optical path-elongation factor $D_{\mathrm{u}}^{\mathrm{b}}$ for the bottom mainly depends on the bottom reflectance. These factors are defined as

$$
\begin{aligned}
& \left.D_{\mathrm{u}}^{\mathrm{c}}=1.03 \sqrt{(1+(2.4 \times u)}\right), \\
& \left.D_{\mathrm{u}}^{\mathrm{b}}=1.04 \sqrt{(1+(5.4 \times u)}\right) .
\end{aligned}
$$

$r_{\text {rs }}$ is the subsurface remote-sensing reflectance which is a function of the IOPs at a given depth and expressed as

$r_{\mathrm{rs}}=u \times[(u \times 0.170)+0.084]$.

Also, $\theta_{\mathrm{w}}$ is the subsurface solar zenith angle, $H$ is the bottom depth, $R_{\text {effbtm }}$ is the effective bottom reflectance and $\kappa$ and $u$ are the inherent optical parameters which can be obtained from

$$
\begin{gathered}
u=\frac{b_{\mathrm{b}}(z)}{a(z)+b_{\mathrm{b}}(z)}, \\
\kappa=a(z)+b_{\mathrm{b}}(z) .
\end{gathered}
$$

Based on the IOPs along the depth and effective reflectance of the bottom, the reflectance functions along the depth $R(z)$ can be calculated from these equations.

\section{Source function}

Since the source function affects the underwater light fields (by way of re-emitting photons by phytoplankton at longer wavelengths after absorption at shorter wavelengths), it is also included in the present RT model. The source function can be computed as follows (Gower et al., 2004):

$\mathrm{Fl}(\lambda)=\frac{0.15 \times \mathrm{Chl}}{1+0.2 \times \mathrm{Chl}}$.

The source function is calculated as a function of the chlorophyll fluorescence as follows:

$S(\lambda)=\operatorname{Fl}(\lambda) \times h(\lambda)$,

where $h(\lambda)$ is the fluorescence emission function per unit wavelength calculated based on the Gaussian distribution,

$h(\lambda)=\frac{1}{\sqrt{2 \pi \sigma^{2}}} \exp \left(-\frac{\left(\lambda-\lambda_{0}\right)^{2}}{2 \sigma^{2}}\right)$.

The wavelength of maximum emission is $\lambda_{0}=0.685 \mu \mathrm{m}$ and the standard deviation $\sigma=0.011 \mu \mathrm{m}$.

\subsubsection{Inhomogeneous term: underwater light-field parameters}

The downwelling irradiance $E_{\mathrm{d}}\left(0^{-}\right)$just below the water for the inhomogeneous (or layer by layer) condition can be calculated from the downwelling irradiance $E_{\mathrm{d}}\left(0^{+}\right)$just above the water along with the transmittance derived from the Fresnel equation (Eq. 7),

$E_{\mathrm{d}}\left(0^{-}\right)=E_{\mathrm{d}}\left(0^{+}\right) \times \mathrm{Tx}_{\mathrm{F}}$. 
Once the downwelling irradiance is transmitted through the water surface, the intensity of the downwelling irradiance based on the transmittance is purely dependent on the IOPs. The downwelling irradiances for the first and subsequent layers of the depth are calculated from

$$
E_{\mathrm{d}}\left(z_{1}\right)=E_{\mathrm{d}}\left(0^{-}\right) ; E_{\mathrm{d}}\left(z_{2}\right)=E_{\mathrm{d}}\left(z_{1}\right) \times \operatorname{Tx}\left(z_{2}\right) .
$$

The downwelling irradiance along the depth can be calculated from an explicit method with the corresponding depth transmittance $\operatorname{Tx}(z)$. The common equation for calculating $E_{\mathrm{d}}(z)$ along the depth is given as

$E_{\mathrm{d}}(z)=E_{\mathrm{d}}(z-1) \times \operatorname{Tx}(z)$.

The upwelling irradiances below the water along the depth are calculated from

$E_{\mathrm{u}}(z)=\left(E_{\mathrm{d}}(z) \times R(z)\right)$,

where $E_{\mathrm{d}}(z)$ is downwelling irradiance and $R(z)$ is the reflectance for the corresponding depth which includes the effect of the bottom reflectance and IOPs from the bottom boundary condition.

\subsubsection{Homogeneous term: underwater light-field parameters}

The downwelling irradiance equation developed by Haltrin (1998b) for the homogenous water column takes the following expression,

$$
\begin{gathered}
\mathrm{HE}_{\mathrm{d}}(z)=E_{\mathrm{d}}^{0} \exp \left(-\alpha_{\infty} z\right)+E_{\mathrm{s}}^{\perp} \exp \left(-\alpha z / \mu_{\mathrm{s}}\right) \\
+E_{\mathrm{s}}^{\perp} h R_{\mathrm{s}}\left\{1+\mu_{\mathrm{s}}(2+\bar{\mu})\right\} F_{\mathrm{s}}(z) \exp \left(-\alpha_{\infty} z\right) .
\end{gathered}
$$

The upwelling irradiance for the homogenous water column can be calculated with the equation of Haltrin (1998b):

$$
\begin{aligned}
& \mathrm{HE}_{\mathrm{u}}(z)= \\
& E_{\mathrm{d}}^{0} R_{\infty} \exp \left(-\alpha_{\infty} z\right)+\mu_{\mathrm{s}} E_{\mathrm{s}}^{\perp} R_{\infty} \exp \left(-\alpha z / \mu_{\mathrm{s}}\right) \\
& +E_{\mathrm{s}}^{\perp} h R_{\mathrm{s}}\left\{\mu_{\mathrm{s}}(2-\bar{\mu})-1\right\} F_{\mathrm{s}}(z) \exp \left(-\alpha_{\infty} z\right) .
\end{aligned}
$$

The input parameters used in the calculation of $\mathrm{HE}_{\mathrm{d}}$ and $\mathrm{HE}_{\mathrm{u}}$ are explained in the transmittance section. Here, $E_{\mathrm{s}}$ is the diffuse term of the above-water irradiance which is obtained from the sky radiance $L_{\text {sky }}$. The total underwater lightfield parameters $\left(E_{\mathrm{d}}, E_{\mathrm{u}}\right.$ and $\left.L_{\mathrm{u}}\right)$ can be obtained by applying Eqs. (26)-(29) in Eqs. (2)-(4). The model presented in this study is much easier to implement when compared to the existing RT models.

\subsection{Prediction of remotely sensed IOPs along the water column}

\subsubsection{Bio-optical model}

This section presents methods to estimate the surface chlorophyll $[\mathrm{Chl}]_{\text {sur }}$ and suspended sediments $[\mathrm{SS}]_{\text {sur }}$ (concentrations) from the normalised water-leaving radiance $\left(\mathrm{nL}_{\mathrm{w}}\right)$.
The slope values $\left(S_{\mathrm{nLw}}\right)$ required for fixing the threshold limit (i.e., scenarios in Table 3 ) for different waters are calculated as follows:

$S_{\mathrm{nLw}}=100 \times\left[\frac{\mathrm{nL}_{\mathrm{w}}(0.443)-\mathrm{nL}_{\mathrm{w}}(0.547)}{0.443-0.547}\right]$.

Since the normalised water-leaving radiance values are larger than the remote-sensing reflectance, the former quantity is used to better determine the used scenarios (Ahn and Shanmugam, 2006; Shanmugam, 2011b). Based on the $S_{\mathrm{nLw}}$ and $\mathrm{nL}_{\mathrm{w}}$ data, three scenarios are found adequate for the various water types. The first scenario represents the open-ocean waters where $S_{\mathrm{nLw}}$ is less than 0.5 and [Chl] is based on the ratio of $R_{\mathrm{rs}}(0.488)$ and $R_{\mathrm{rs}}(0.547)$ (Table 3$)$. The second scenario indicates turbid coastal waters where the same band ratio is used for the [Chl] parameterisation. The [SS] parameterisations are different for both these scenarios. The third scenario is developed for inland and eutrophic waters based on the exponential function that uses the $R_{\mathrm{rs}}$ values at three different bands $(0.690,0.700$ and $0.760 \mu \mathrm{m})$ (Zhang et al., 2009). The coefficients of the exponential equation are obtained based on the $\mathrm{IR}_{\mathrm{rs}}$ value which is defined as follows:

$\mathrm{IR}_{\mathrm{rs}}=\left(\frac{1}{R_{\mathrm{rs}}(0.690)}-\frac{1}{R_{\mathrm{rs}}(0.700)}\right) \times R_{\mathrm{rs}}(0.760)$.

For the [SS] parameterisation, there is a shift of peak between 0.547 and $0.488 \mu \mathrm{m}$ in clear waters (first scenario) and the ratio of $R_{\mathrm{rs}}(0.620)$ to the maximum value of $R_{\mathrm{rs}}(0.488)$ and $R_{\mathrm{rs}}(0.547)$ is found to be suitable for these waters. In turbid coastal waters (second scenario), the reflectance peak at $0.547 \mu \mathrm{m}$ dominates the $R_{\mathrm{rs}}$ values at $0.488 \mu \mathrm{m}$ and the relative change of these values is used in terms of the ratio to estimate [SS] in turbid waters. Considering inland and eutrophic waters (third scenario), the ratio of $R_{\mathrm{rs}}$ at 0.620 and $0.720 \mu \mathrm{m}$ is used for the estimation of [SS] in these waters.

\subsubsection{Vertical profiles of chlorophyll and suspended sediments}

The chlorophyll and suspended sediments along the vertical column are determined from the surface [Chl] and [SS] data. For the chlorophyll profile, Lewis et el. (1983) found the generalised Gaussian distribution model which captures the major features of the observed vertical profile. The major parameters used to determine the chlorophyll profile are the surface chlorophyll [Chl $]_{\text {sur }}$, maximum chlorophyll [Chl $]_{\max }$, depth chlorophyll maximum $Z_{\max }$ and $\sigma$ (standard deviation that controls the thickness of the $[\mathrm{Chl}]_{\max }$ layer and determines the vertical spread). The $[\mathrm{Chl}]_{\max }$ is the value of maximum chlorophyll in the water column and $Z_{\max }$ is the depth of $[\mathrm{Chl}]_{\max }$. The schematic representation of these chlorophyll profile parameters is shown in Fig. 3. The determination of the chlorophyll profile based on the above parameters 
Table 2. Station details and the observed environmental parameters used for this study.

\begin{tabular}{|c|c|c|c|c|c|c|c|c|c|c|}
\hline Station & Date & Time (LT) & Latitude & Longitude & $\theta_{z}$ & $\begin{array}{l}\text { Depth } \\
\text { (m) }\end{array}$ & $\begin{array}{l}U \\
\left(\mathrm{~ms}^{-1}\right)\end{array}$ & $\begin{array}{l}{[\mathrm{Chl}]} \\
\left(\mathrm{mg} \mathrm{m}^{-3}\right)\end{array}$ & $\begin{array}{l}{[\mathrm{SS}]} \\
\left(\mathrm{mg} \mathrm{m}^{-3}\right)\end{array}$ & $\begin{array}{r}a_{\mathrm{CDOM}}(490) \\
\left(\mathrm{m}^{-1}\right)\end{array}$ \\
\hline St-1 & $31 / 08 / 2013$ & $13: 00$ & $13^{\circ} 08.715 \mathrm{~N}$ & $80^{\circ} 21.041 \mathrm{E}$ & 21.9 & 19.8 & 7.7 & $0.2-1.1$ & $7.9-17.7$ & 0.181 \\
\hline St-2 & $31 / 08 / 2013$ & $15: 00$ & $13^{\circ} 08.715 \mathrm{~N}$ & $80^{\circ} 21.041 \mathrm{E}$ & 43.6 & 19.8 & 7.7 & $0.3-0.5$ & $8.2-11.1$ & 0.175 \\
\hline St-3 & $26 / 08 / 2013$ & $15: 00$ & $10^{\circ} 20.714 \mathrm{~N}$ & $80^{\circ} 08.604 \mathrm{E}$ & 43.2 & 17.7 & 5 & $1.0-6.7$ & $7.0-15.8$ & 0.83 \\
\hline St-4 & $26 / 08 / 2013$ & $11: 45$ & $10^{\circ} 22.103 \mathrm{~N}$ & $79^{\circ} 57.720 \mathrm{E}$ & 4.55 & 6.3 & 7.7 & $0.8-2.3$ & $33.8-41.9$ & 1.15 \\
\hline St-5 & $17 / 08 / 2012$ & $15: 10$ & $10^{\circ} 20.992 \mathrm{~N}$ & $80^{\circ} 05.573 \mathrm{E}$ & 44.9 & 17.9 & 4 & $6.2-18.5$ & $10.9-15.7$ & 0.92 \\
\hline St-6 & $17 / 08 / 2012$ & $15: 55$ & $10^{\circ} 20.714 \mathrm{~N}$ & $80^{\circ} 08.604 \mathrm{E}$ & 55.9 & 22 & 3 & $5.3-20.4$ & $8.4-16.6$ & 0.85 \\
\hline St-7 & $08 / 11 / 2013$ & $14: 00$ & $13^{\circ} 07.408 \mathrm{~N}$ & $80^{\circ} 17.565 \mathrm{E}$ & 42.8 & 5 & 0.25 & $18.3-18.5$ & $21.6-24.0$ & 0.98 \\
\hline St-8 & $10 / 11 / 2013$ & $14: 50$ & $12^{\circ} 48.474 \mathrm{~N}$ & $80^{\circ} 14.204 \mathrm{E}$ & 53.2 & 1 & 0.25 & 52.5 & $70.4-71.6$ & 1.48 \\
\hline St-9 & $10 / 11 / 2013$ & $15: 10$ & $12^{\circ} 48.321 \mathrm{~N}$ & $80^{\circ} 14.239 \mathrm{E}$ & 59.5 & 1 & 0.25 & 54.1 & $68.2-87.3$ & 1.51 \\
\hline St-10 & $16 / 12 / 2013$ & $13: 15$ & $12^{\circ} 48.474 \mathrm{~N}$ & $80^{\circ} 14.204 \mathrm{E}$ & 42.5 & 1 & 0.25 & 72.1 & $63.6-65.5$ & 1.34 \\
\hline St-11 & $16 / 12 / 2013$ & $13: 30$ & $12^{\circ} 48.321 \mathrm{~N}$ & $80^{\circ} 14.239 \mathrm{E}$ & 43.8 & 1 & 0.25 & 73.8 & $62.1-64.8$ & 1.25 \\
\hline
\end{tabular}

Table 3. Empirical relationships between the in situ $R_{\mathrm{rs}}$ and in situ surface concentration $\left([\mathrm{Chl}]_{\text {sur }}\right.$ and $\left.[\mathrm{SS}]_{\text {sur }}\right)$ in a variety of waters for three different scenarios. Note that S.No. 3 will have another expression $[\mathrm{Chl}]_{\mathrm{sur}}=17.128 \times \exp \left(0.888 \times \mathrm{IR}_{\mathrm{rs}}\right)$ if one intends to use $R_{\mathrm{rs}}(0.680)$ instead of $R_{\mathrm{rs}}(0.690)$ in Eq. (37). The empirical coefficients presented in this table are derived based on our in situ data.

\begin{tabular}{lll}
\hline$[\mathrm{CHL}]_{\text {sur }}$ & {$[\mathrm{SS}]_{\mathrm{sur}}$} & Scenario \\
\hline $1.123 \times\left(\frac{R_{\mathrm{r}}(0.488)}{R_{\mathrm{rs}}(0.547)}\right)^{-3.7144}$ & $21.503 \times\left(\frac{R_{\mathrm{rs}}(0.620)}{\max \left[R_{\mathrm{rs}}(0.488), R_{\mathrm{rs}}(0.547)\right]}\right)^{0.3998}$ & $S_{\mathrm{nLw}}<0.5$ \\
\hline $0.409 \times\left(\frac{R_{\mathrm{r}}(0.488)}{R_{\mathrm{rs}}(0.547)}\right)^{-7.567}$ & $34.01 \times\left(\frac{R_{\mathrm{rr}}(0.547)}{R_{\mathrm{rs}}(0.488)}\right)^{-1.2615}$ & $S_{\mathrm{nLw}}>0.5$ \\
\hline $18.267 \times \exp (1.9913 \times \mathrm{IR} \mathrm{rs})$ & $38.685 \times\left(\frac{R_{\mathrm{rr}}(0.620)}{R_{\mathrm{rs}}(0.720)}\right)^{-0.554}$ & $\begin{array}{l}R_{\mathrm{rs}}(0.547)>R_{\mathrm{rs}}(0.488) \& \\
R_{\mathrm{rs}}(0.680)<R_{\mathrm{rs}}(0.690)\end{array}$ \\
\hline
\end{tabular}

is given below:

$\operatorname{Chl}(z)=\mathrm{Chl}_{\text {sur }}+\mathrm{Chl}_{\max } \times \exp \left[-\frac{\left(z-z_{\max }\right)^{2}}{2 \sigma^{2}}\right]$.

The chlorophyll profile parameters calculated from the surface [Chl] are shown in Table 4 and the basic equations are taken from Gokul et al. (2014). The equations were developed based on a large number of in situ data. Conversely, the SS profile is estimated using the power-law function,

$\mathrm{SS}(z)=\mathrm{SS}_{\mathrm{sur}} \times\left(\frac{z}{z_{\text {sur }}}\right)^{0.0383}$

The slope is calculated based on the mean slope values from a number of measured SS profiles. Here, the $\mathrm{SS}_{\mathrm{sur}}$ of the concentration of suspended sediments at the near surface and $Z_{\text {sur }}$ is the depth at which the $\mathrm{SS}_{\text {sur }}$ is measured $\left(Z_{\text {sur }}=1 \mathrm{~m}\right)$.

\subsubsection{IOP model}

\section{Clear and turbid coastal waters}

A simplified model is used to estimate the vertical profiles of IOPs using chlorophyll and suspended sediment profile data. Though the IOPs may be determined by more than three sub-

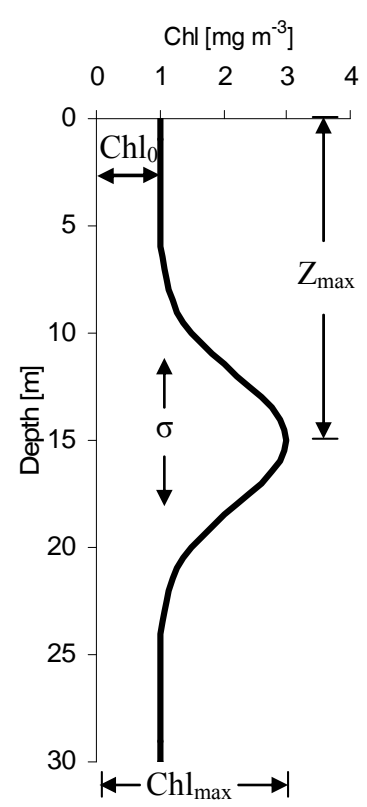

Figure 3. Schematic diagram represents the vertical profile of the chlorophyll along the depth including the distribution of profile parameters using the Gaussian distribution function. 
Table 4. Empirical relationships of the chlorophyll profile parameters ([Chl $]_{\max }, Z_{\max }$ and $\sigma$ ) for the various ranges of surface chlorophyll $[\mathrm{Chl}]_{\text {sur }}$ from different stations.

\begin{tabular}{llll}
\hline $\mathrm{Chl}_{\text {sur }}$ & $\mathrm{Chl}_{\max }$ & $Z_{\max }$ & $\Sigma$ \\
\hline $1.0<\mathrm{Chl}_{\text {sur }}<10$ & $2.019 \times \mathrm{Ch}_{\text {sur }}-0.2328$ & $0.7595 \times \mathrm{Chl}_{\text {sur }}+4.082$ & $0.3456 \times \mathrm{Chl}_{\text {sur }}+4.104$ \\
$0.5<\mathrm{Ch}_{\text {sur }}<1$ & $-8.288 \times \mathrm{Chl}_{\text {sur }}+8.3628$ & $-12.247 \times \mathrm{Chl}_{\text {sur }}+15.479$ & $3.1606 \times \mathrm{Ch}_{\text {sur }}-0.199$ \\
$0<\mathrm{Chl}_{\text {sur }}<0.5$ & $-8.288 \times \mathrm{Chl}_{\text {sur }}+2.6628$ & $-12.247 \times \mathrm{Chl}_{\text {sur }}+15.479$ & $3.1606 \times \mathrm{Chl}_{\text {sur }}-0.199$ \\
\hline
\end{tabular}

stances, it is assumed that the absorption and scattering coefficients in clear and turbid coastal waters are mainly determined by water itself, suspended sediment particles and phytoplankton (both living and non-living). Thus, the total absorption coefficient of seawater, $a(\lambda, z)$, is the sum of the absorption of seawater $a_{\mathrm{W}}(\lambda, z)$, dissolved organic $a_{\mathrm{CDOM}}(\lambda, z)$, and particulate matter $a_{\mathrm{p}}(\lambda, z)$. The total absorption coefficient observed at any given wavelength can be expressed as

$$
\begin{aligned}
a(\lambda, z) & =a_{\mathrm{w}}(\lambda, z)+a_{\mathrm{CDOM}}(\lambda, z)+a_{\mathrm{p}}(\lambda, z), \\
a_{\mathrm{p}}(\lambda, z) & =a_{\mathrm{ph}}(\lambda, z)+a_{\mathrm{ss}}(\lambda, z) .
\end{aligned}
$$

Here the total absorption (pure water, chlorophyll, suspended sediments and coloured dissolved organic matter) is estimated from Morel (1991) and the absorption coefficient of suspended sediments is calculated from Gokul et al. (2014):

$$
\begin{aligned}
a(\lambda, z)= & \left(a_{\mathrm{w}}(\lambda)+0.06 a_{C}^{*}(\lambda)[\operatorname{Chl}(z)]^{0.65}\right) \\
& \times\left(1+0.2 \exp \left(-0.014(\lambda-0.400) \times 10^{-3}\right)\right) \\
& +a_{\mathrm{ss}}(\lambda, z) .
\end{aligned}
$$

The seawater absorption coefficients were taken from Pope and Fry (1997). The absorption coefficient of suspended sediments is estimated as follows:

$a_{\mathrm{ss}}(\lambda, z)=a_{\mathrm{ss}}\left(\lambda_{r}\right) \times \exp \left(-0.0104\left(\lambda-\lambda_{r}\right)\right)$,

where the absorption at a reference wavelength $0.443 \mu \mathrm{m}$ is calculated from the power fit shown in Fig. 4 a and the equation is given as

$a_{\mathrm{ss}}(0.443)=0.0007[\mathrm{SS}(z)]^{1.7653}, \quad\left[R^{2}=0.9\right]$.

Similarly, the total scattering coefficient of sea water is the sum of the scattering due to pure seawater $b_{\mathrm{w}}(\lambda, z)$ and particulate matter $b_{\mathrm{p}}(\lambda, z)$ (due to phytoplankton and suspended sediments). The pure sea water scattering coefficients were taken from Smith and Baker (1981). Since the contribution of CDOM is negligible, it is omitted leading to the total scattering $b(\lambda, z)$,

$b(\lambda, z)=b_{\mathrm{w}}(\lambda, z)+b_{\mathrm{ph}}(\lambda, z)+b_{\mathrm{ss}}(\lambda, z)$.
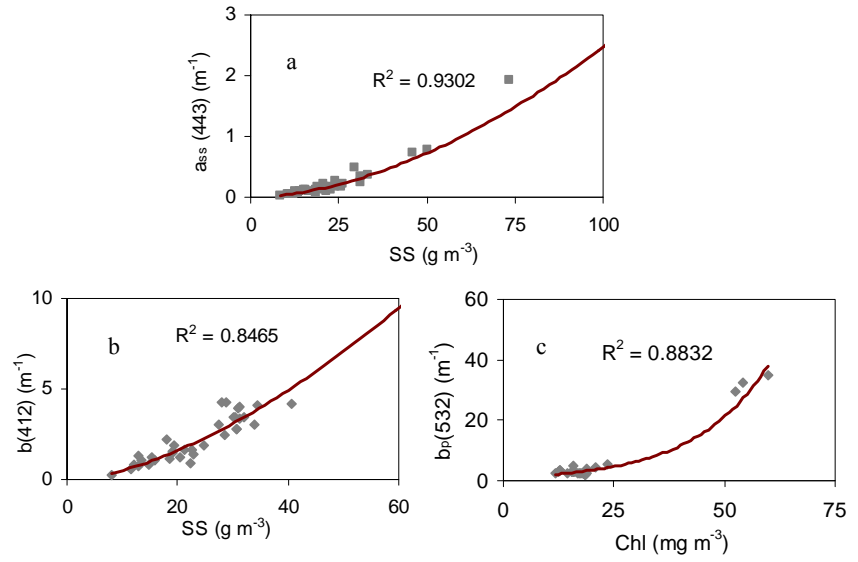

Figure 4. (a) Relationship between the suspended sediment concentration and absorption by suspended sediment $a_{\mathrm{ss}}(443)$, used to calculate the absorption coefficient of suspended sediments $a_{\mathrm{ss}}(443)$. (b) Relationship between the suspended sediment concentration and scattering $b(412)$, used to calculate the scattering $\left(b_{\mathrm{ss}}\right)$ coefficient of suspended sediments. (c) Relationship between the Chlorophyll and particulate scattering $b_{\mathrm{p}}(532)$ which is used to calculate the particulate scattering directly from the chlorophyll concentration. This is applicable only for surface Chl should it be greater than $15 \mathrm{mg} \mathrm{m}^{-3}$.

The scattering due to phytoplankton $\left(b_{\mathrm{ph}}\right)$ depends on the chlorophyll concentration which is derived from Gordon and Morel (1983):

$b_{\mathrm{ph}}(\lambda, z)=\left(\frac{0.550}{\lambda}\right)^{S} \times\left(0.3[\mathrm{Chl}(z)]^{-0.3}\right)$,

where $S$ is the slope which is calculated based on the chlorophyll concentration (Huot et al., 2008). When the Chl is greater than $2 \mathrm{mg} \mathrm{m}^{-3}, S$ is considered to be zero. If Chl is less than $2 \mathrm{mg} \mathrm{m}^{-3}$, the slope will be calculated from the following equation:

$S=0.5 \times(\log ([\operatorname{Chl}(z)])-0.3)$.

The scattering due to suspended sediments is estimated using the power-law model (Fig. 4b) which is expressed as

$b_{\mathrm{ss}}(\lambda, z)=\frac{1}{2}\left(\frac{0.412}{\lambda}\right)^{0.88} \times\left(0.0043[\mathrm{SS}(z)]^{1.9657}\right)$.

Finally, the attenuation coefficients $\alpha(\lambda, z)(=c(\lambda, z))$ are calculated based on the total absorption $a(\lambda, z)$ and total scattering $b(\lambda, z)$ coefficients. 
Table 5. New spectral absorption coefficients of water particles derived from the in situ data, which are used only when the concentration of $[\mathrm{Chl}]_{\text {sur }}$ is greater than $15 \mathrm{mg} \mathrm{m}^{-3}$, for the calculation of the particulate absorption.

\begin{tabular}{llll}
\hline $\begin{array}{l}\text { Wavelength } \\
(\mu \mathrm{m})\end{array}$ & $a_{\mathrm{p}}^{*}$ & $\begin{array}{l}\text { Wavelength } \\
(\mu \mathrm{m})\end{array}$ & $a_{\mathrm{p}}^{*}$ \\
\hline 0.401 & 0.195342 & 0.575 & 0.038799 \\
0.425 & 0.208779 & 0.601 & 0.044386 \\
0.451 & 0.168103 & 0.625 & 0.056005 \\
0.475 & 0.129094 & 0.651 & 0.053105 \\
0.501 & 0.098007 & 0.675 & 0.080339 \\
0.525 & 0.061625 & 0.701 & 0.019868 \\
0.551 & 0.042149 & 0.725 & 0.002783 \\
\hline
\end{tabular}

\section{Eutrophic and phytoplankton-dominated waters}

For eutrophic and phytoplankton-dominated waters, the variations in absorption and scattering coefficients are poorly documented as most of the previous studies on IOPs were conducted in relatively clear and open-ocean waters. In this study, absorption and scattering by particles are estimated using separate models for these waters. In the previous studies, phytoplankton absorption $a_{\mathrm{ph}}(\lambda)$ was generally calculated based on the specific phytoplankton absorption $a_{\mathrm{ph}}^{*}(\lambda)$. Here the specific particulate absorption coefficients $a_{\mathrm{p}}^{*}(\lambda)$ are used to calculate the particulate absorption coefficients $a_{\mathrm{p}}(\lambda)$. The values of new $a_{\mathrm{p}}^{*}(\lambda)$ are given in Table 5 . The particulate absorption coefficients are then derived as a function of chlorophyll as follows:

$a_{\mathrm{p}}(\lambda, z)=a_{\mathrm{p}}^{*}(\lambda) \times[\mathrm{Chl}(z)] \times\left(\frac{[\mathrm{Chl}(z)]}{54}\right)$.

Similarly, the particulate scattering is calculated directly based on the exponential function of chlorophyll (Fig. 4c) as follows:

$b_{\mathrm{p}}(\lambda, z)=$

$1.4 \times \exp (0.0525 \times[\mathrm{Chl}(z)]) \times\left(\frac{\lambda}{0.532}\right)^{-0.3}$.

This equation is derived from the relationship between in situ chlorophyll and particulate scattering ( $c-a$ from WetLabs AC-S). Both particulate absorption and scattering coefficients are added with the respective pure water coefficients to obtain the total absorption and scattering coefficients.

\section{Results and discussion}

Results are categorised into four parts: (1) comparison of the model versus measured IOP profile data, (2) effects of homogeneous and inhomogeneous water column conditions, (3) comparison of the underwater light fields predicted by the
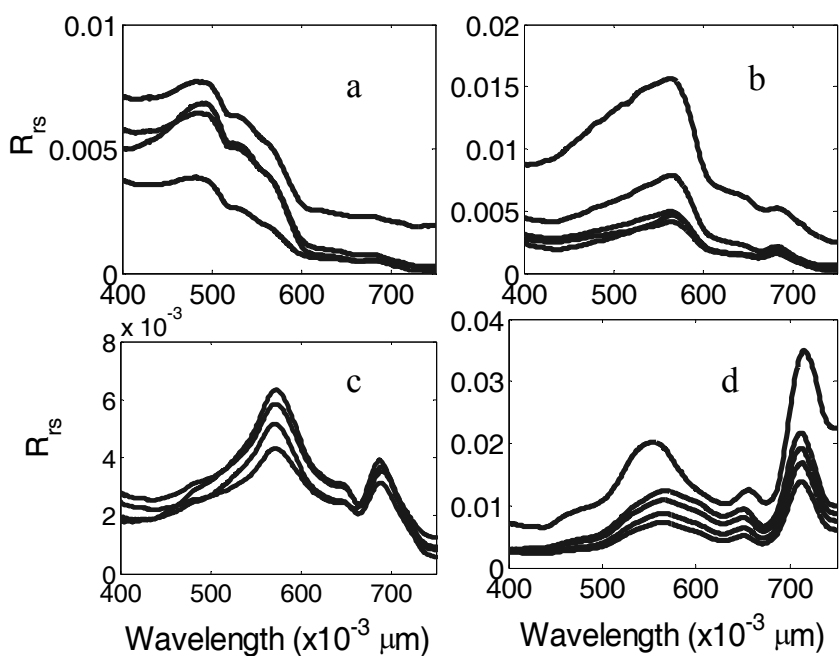

Figure 5. The typical remote-sensing reflectance spectra $R_{\mathrm{rs}}(\lambda)$ measured at four stations in the study area during 2012 and 2013. (a) Relatively clear waters off Chennai, (b) moderately turbid waters off Point Calimere, (c) phytoplankton-dominated harbour waters of Chennai and (d) eutrophic waters.

RT model, based on the measured and estimated IOP profiles from remote-sensing data, and (4) apparent optical properties from underwater light fields. Figure 5 shows the examples of measured remote-sensing reflectances from different waters (clear, turbid and eutrophic waters) used for construction of the vertical profiles of IOPs and simulation of the underwater light fields. The specific spectral features of IOPs for these waters have already been described in a recent study (Pravin and Shanmugam, 2014). It should be mentioned that the underwater light-field parameters are simulated from the RT model using MATLAB 2007 with a 4 gigabyte RAM computer. The run time for this model is 8 milliseconds for the entire wavelength at one depth for a given sample. In fact, this can be reduced if the model is implemented in FORTRAN with a high performance computer. The performance of the model in simulating the underwater light-field parameters is assessed using the mean relative error $(\mathrm{MRE}=$ (model - in situ)/in situ).

\subsection{Prediction of the IOP profiles from remote-sensing data}

This section is focused on the determination of the vertical profiles of IOPs based on the seawater constituents (chlorophyll and suspended sediments at the surface level) that are estimated from the above-water remote-sensing reflectance $\left(R_{\mathrm{rs}}\right)$ data.

\subsubsection{Retrieval of the seawater constituents}

The spectral information of the remote-sensing reflectance $\left(R_{\mathrm{rs}}\right)$ was used to estimate [Chl] and [SS] in surface wa- 

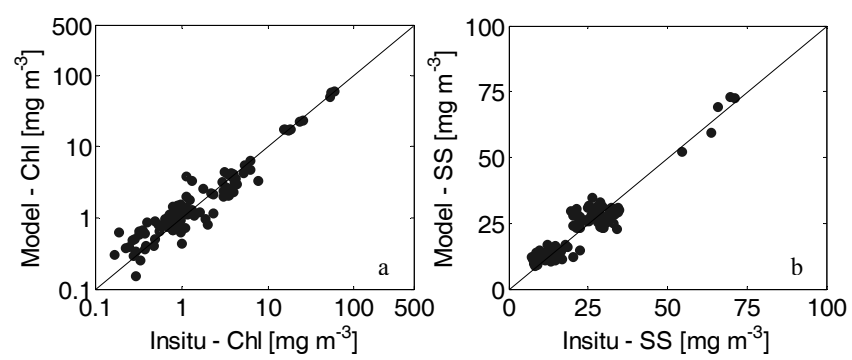

Figure 6. (a) Scatter plot showing the comparison of the estimated chlorophyll concentration from the remote-sensing reflectance $R_{\mathrm{rs}}$ with the in situ chlorophyll from different waters. (b) Scatter plot showing the comparison of the estimated suspended sediment concentration from the remote-sensing reflectance $R_{\mathrm{rs}}$ with the in situ suspended sediment concentration from different waters.

ters off Point Calimere and Chennai. Since the models are based on the different spectral slopes of $R_{\mathrm{rs}}$, different scenarios were used to estimate these water constituents accurately. The estimated [Chl] and [SS] show good agreement with measured data from different waters (Fig. 6a), where [Chl] ranged from 0.1 to $100 \mathrm{mg} \mathrm{m}^{-3}$. The statistics analyses indicate low errors and high slopes and correlation coefficients $(\mathrm{MRE}=0.17, \mathrm{RMSE}=0.18$, slope $=1.0$, bias $\left.=-0.031, R^{2}=0.91, \mathrm{~N}=98\right)$. Similarly, the estimated [SS] agree closely with the in situ [SS] (Fig. 6b), with good statistics $(\mathrm{MRE}=0.01$, RMSE $=0.09$, slope $=0.98$, bias $\left.=-0.01, R^{2}=0.84, N=98\right)$. These results clearly demonstrate consistency between the estimated and measured data for a wide range of waters.

\subsubsection{Vertical profiles of chlorophyll and suspended sediments}

On the basis of surface chlorophyll $[\mathrm{Chl}]_{\text {surf }}$ and [SS] estimated from remote-sensing data, the vertical profiles of $[\mathrm{Chl}(z)]$ and $[\mathrm{SS}(z)]$ were constructed in relatively clear and turbid coastal waters. It is observed that the modelled and measured chlorophyll profiles agree well in relatively clear waters off Chennai (31 August 2013 at 13:00 and 15:00 LT) (Fig. 7a and b). The Chl concentration is low in surface waters $\left(0.3 \mathrm{mg} \mathrm{m}^{-3}\right)$ and gradually increases along the depth. For relatively clear waters off Point Calimere in August 2013 (Fig. 7c), the surface chlorophyll is very low $\left(0.8 \mathrm{mg} \mathrm{m}^{-3}\right)$ and the depth of chlorophyll maximum $\left(Z_{\max }\right)$ shifts to the seabed exponentially. This profile is the indication of more light attenuation towards the sea bed. The subsurface chlorophyll maximum $[\mathrm{Chl}]_{\max }$ might occur due to the influences of benthic resuspension caused by tides and currents. Though the modelled chlorophyll profile typically follows the measured chlorophyll profile at this station, there is a slight deviation of the modelled chlorophyll profile observed at the intermediate depth. The $[\mathrm{Chl}]_{\text {surf }}$ in surface waters off Point Calimere is relatively high $\left(5 \mathrm{mg} \mathrm{m}^{-3}\right)$ during August 2012
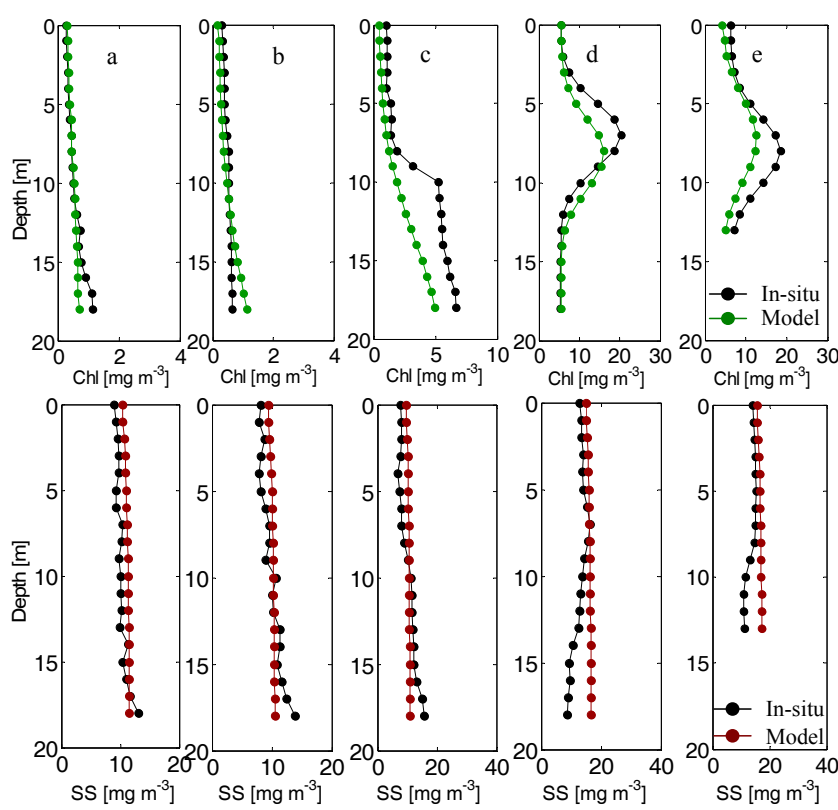

Figure 7. The examples of the modelled and measured vertical profiles of $[\mathrm{Chl}(z)]$ for five different cases (top row). (a and b) St-1 and St-2 from relatively clear waters off Chennai, (c) St-4 from moderately turbid water with chlorophyll settled at the bottom of seabed. (d and e) St-6 and St-5 from the chlorophyll-dominated regions. The second row shows the modelled and measured vertical profiles of $[\mathrm{SS}(z)]$ for the same locations. The $[\mathrm{SS}(z)]$ modelled profiles are almost uniform along the depth.

(Fig. 7d). As the depth increases, [Chl] increases with a maximum value $\left([\mathrm{Chl}]_{\max }\right)$ around $7 \mathrm{~m}$ depth $\left(20 \mathrm{mg} \mathrm{m}^{-3}\right)$ and then decreases following the surface $[\mathrm{Chl}]_{\text {surf }}$. This trend typically follows the Gaussian distribution function, and thus there is better consistency between the modelled and measured Chl profiles (Fig. 7e). Another station towards the coast of Point Calimere during the same period was found to have a similar Gaussian profile indicating that the euphotic zone lies horizontally at a depth of $7 \mathrm{~m}$. The corresponding measured and modelled SS profiles [SS $(z)]$ are shown in Fig. 7a-c for these stations. Generally, the measured [SS] profiles are uniform along the depth and the power-law function captures their depth variations adequately.

\subsubsection{Modelling of IOPs based on the $\mathrm{Chl}$ and SS profiles}

The $[\mathrm{Chl}(z)]$ and $[\mathrm{SS}(z)]$ profiles constructed from the models were used to estimate the IOP profiles. Figure 8 shows the comparison of estimated (black colour) and predicted (grey colour) IOPs (plotted for three wavelengths $0.440,0.555$ and $0.676 \mu \mathrm{m}$ ) with the in situ IOP data, where the three clusters correspond to different waters (bottom - clear waters, middle - turbid coastal waters, top - eutrophic waters). Since a wide variety of waters is considered in this study, separate models were developed to treat the different water types. In Fig. 8 

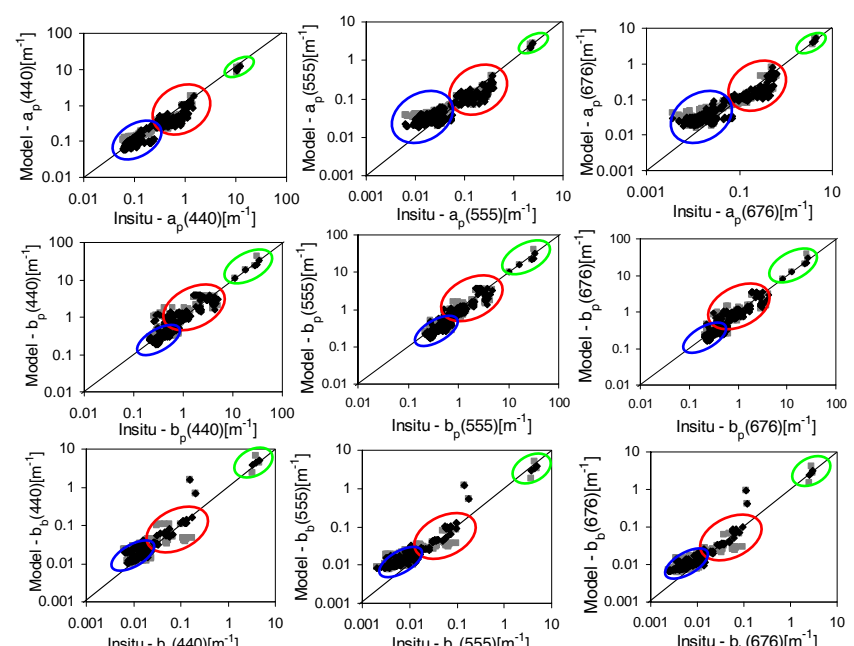

Insitu - $b_{b}(440)\left[m^{-1}\right]$

-Data from eutrophic lagoon waters

-Data from turbid coastal waters

-Data from clear waters

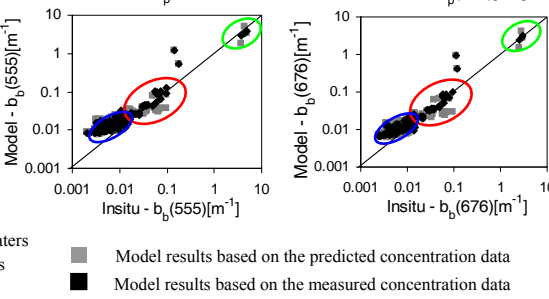

Figure 8. Comparisons of the modelled and in situ IOP data (particulate absorption $a_{\mathrm{p}}$, particulate scattering $b_{\mathrm{p}}$, and backscattering $b_{\mathrm{b}}$ ) at three wavelengths: $0.440,0.555$ and $0.676 \mu \mathrm{m}$. Black colour represents model results based on the in situ concentrations ([Chl $(z)]$ and $[\mathrm{SS}(z)])$ and grey colour represents model results from the predicated profile data (from the estimated $\mathrm{Chl}$ and SS concentrations using remote-sensing reflectance data).

(top row), the model provides good estimates of particulate absorption $a_{\mathrm{p}}$ across the entire visible wavelengths (MRE $-0.06-0.0774$ ), although there is a slight overestimation (at higher wavelengths) especially in low-Chl waters. The predicted $a_{\mathrm{p}}$ values are also well consistent with in situ $a_{\mathrm{p}}$ data. Figure 8 (second row) presents the comparison of modelled and measured particulate scattering $b_{\mathrm{p}}$ values (at $0.440,0.555$ and $0.676 \mu \mathrm{m}$ ). Interestingly, the model performs well in different waters with a wide range of chlorophyll concentrations. The MRE values associated with this model are very low $(0.1169$ at $0.440 \mu \mathrm{m}, 0.5816$ at $0.555 \mu \mathrm{m}$, and 0.2316 at $0.676 \mu \mathrm{m})$. Similarly, $b_{\mathrm{p}}$ predicted by the model has low MRE values $(-0.1473$ at $0.440 \mu \mathrm{m}, 0.3152$ at $0.555 \mu \mathrm{m}$ and 0.0726 at $0.676 \mu \mathrm{m})$. Comparison of the modelled backscattering $\left(b_{\mathrm{b}}\right)$ with in situ $b_{\mathrm{b}}$ data (at $0.440,0.555$ and $0.676 \mu \mathrm{m}$ as shown in third row of Fig. 8) shows that the model works slightly better in relatively clear, turbid and eutrophic waters but slightly overestimates $b_{\mathrm{b}}$ values in clear waters. This problem could be attributed to measurement errors in very clear waters. The MRE values are -0.0735 at $0.440 \mu \mathrm{m}$, -0.1309 at $0.555 \mu \mathrm{m}$ and -0.0876 at $0.676 \mu \mathrm{m}$ for the estimated $b_{\mathrm{b}}$ using in situ Chl and SS data and -0.0604 at $0.440 \mu \mathrm{m},-0.1194$ at $0.555 \mu \mathrm{m}$ and -0.0763 at $0.676 \mu \mathrm{m}$ for the predicted $b_{\mathrm{b}}$ using estimated $\mathrm{Chl}$ and SS data.

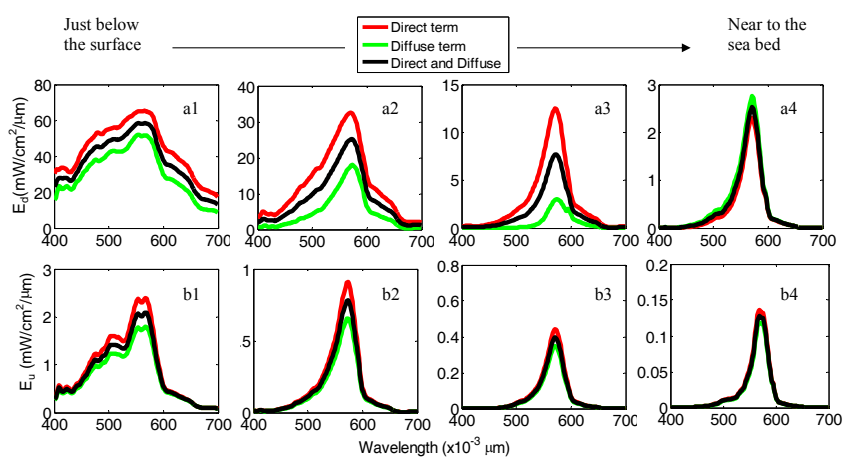

Figure 9. Spectral representation of the direct and diffuse terms of the underwater light fields for four discrete depths (a1-a4 for $E_{\mathrm{d}}$ and b1-b4 for $E_{\mathrm{u}}$ ) in moderately turbid waters off Point Calimere. The red colour represents the direct term, the green colour indicates the diffuse term and the black colour represents the contribution of both direct and diffuse terms in the underwater light fields.

\subsection{Spectral and depth variations of diffuse and direct terms}

This section examines the spectral and depth variations of diffuse and direct terms of the underwater light fields for moderately turbid waters off Point Calimere. As shown in Fig. 9, the magnitude of the direct term (red) is high when compared to the diffuse term (green), especially in the upper and middle layers of the water column. However, as the light propagates through the air-water interface, the contribution of direct term makes a significant change in the downwelling irradiance at consequent depths. The contribution of the diffuse component is less since it is mainly influenced by the water column. Note that the direct and diffuse terms have a large variation in the blue-green region. Thus, considering either one of these terms in RT models is not appropriate in shallow/coastal waters and may lead to large errors along the depth (see Fig. 9a1-a4). To arrive at an approximate solution, the present study considers that both the terms weigh equally. Results of the combined effect of these terms are shown in Fig. 9a1-a4. The diffuse and direct terms are not significantly affected in upwelling irradiance (Fig. 9b1-b4) as compared to those observed in downwelling irradiance. Slight variation is noticed in the direct and diffuse terms of upwelling irradiance at near-surface depths due to the effect of downwelling irradiance. As the depth increases, both these terms generate the spectrum with almost the same magnitude of upwelling irradiance. Results of the combined effect of these two terms on underwater light fields are validated with in situ data and further discussed in the subsequent section.

\subsection{Underwater light-field parameters}

The results of the present RT model (with the consideration of solar zenith angle, sea surface slope, IOP-dependent phase function, bottom slope/material) based on the in situ 

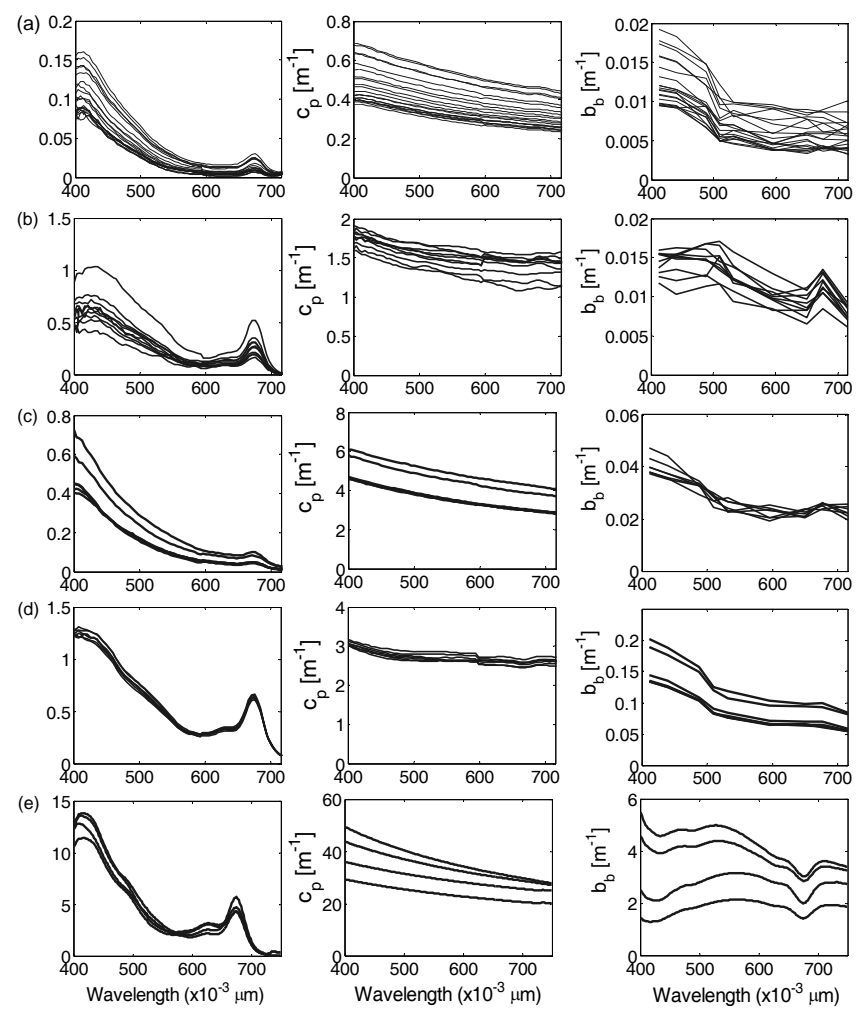

Figure 10. Spectral plots of the in situ IOPs (particulate absorption $a_{\mathrm{p}}$, particulate attenuation $c_{\mathrm{p}}$, and particulate backscattering $b_{\mathrm{b}}$ ) from different waters. (a) Relatively clear waters off Chennai (St1), (b) moderately turbid waters off Point Calimere (St-5), (c) turbid waters off Point Calimere (St-4), (d) phytoplankton-dominated harbour waters off Chennai (St-7) and (e) Eutrophic waters off Chennai (St-8-11).

and predicted IOP profile data are evaluated by comparison with measured underwater radiometric data such as downwelling irradiance $E_{\mathrm{d}}(\lambda, z)$, upwelling irradiance $E_{\mathrm{u}}(\lambda$, $z$ ) and upwelling radiance $L_{\mathrm{u}}(\lambda, z)$. The predicted (from remote-sensing reflectance data) in situ IOP profile data were used as inputs for the present RT model. The IOP data measured from different waters (Fig. 10) include the particulate absorption $\left(a_{\mathrm{p}}\right)$, particulate attenuation $\left(c_{\mathrm{p}}\right)$ and backscattering $\left(b_{\mathrm{b}}\right)$.

\subsubsection{Clear ocean waters}

Figure 11 shows the comparisons of simulated and measured underwater light fields ( $E_{\mathrm{d}}, E_{\mathrm{u}}$ and $L_{\mathrm{u}}$ ) for four discrete water depths in relatively clear waters off Chennai. Looking at the $E_{\mathrm{d}}$ spectra (orange colour - present RT model using in situ IOP data and blue colour - present RT model using Pred IOP data from remote-sensing reflectance), the maximum value is seen at $0.490 \mu \mathrm{m}$ throughout the water column. As the depth increases, $E_{\mathrm{d}}$ becomes attenuated in the blue region $(0.400-0.500 \mu \mathrm{m})$ but progressively more attenuated in the red region $(>0.600 \mu \mathrm{m})$. The $E_{\mathrm{d}}$ values from
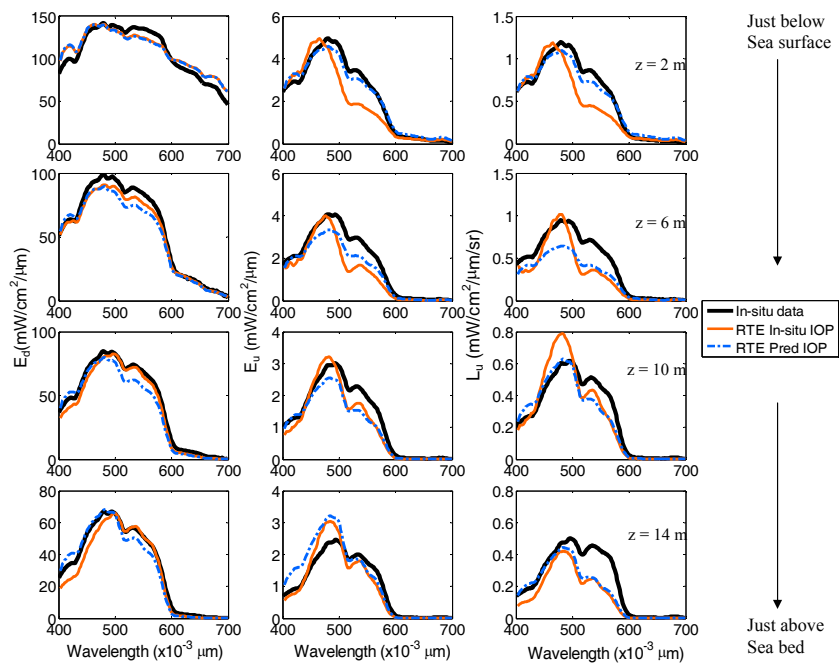

Figure 11. Spectral comparisons of the simulated and measured underwater light fields $\left(E_{\mathrm{d}}, E_{\mathrm{u}}\right.$ and $\left.L_{\mathrm{u}}\right)$ for four discrete depths in clear waters off Chennai (St-1). The black colour represents the measured data, orange colour represents results from the present RT model using in situ IOP data and the blue colour represents results from the present RT model using the predicted IOPs from the remote-sensing reflectance data.

the present RT model using the in situ and predicted IOP data are closely consistent with measured $E_{\mathrm{d}}$ across the entire visible wavelengths. The simulated $E_{\mathrm{d}}$ yields very low MRE (at $0.555 \mu \mathrm{m}$ ), 0.03 and -0.01 for the present RT model using in situ IOP data and predicted IOP data, respectively. Conversely, the spectral pattern of $E_{\mathrm{u}}$ is different from that of $E_{\mathrm{d}}$ (second column) displaying two peaks - one at $0.490 \mu \mathrm{m}$ (primary) and another at $0.520 \mu \mathrm{m}$ (secondary). The $E_{\mathrm{u}}$ from the present RT model using the in situ IOP data closely matches with measured $E_{\mathrm{u}}$ at most wavelengths, except in the region of secondary peak at $0.520 \mu \mathrm{m}$. The MRE (at $0.555 \mu \mathrm{m}$ ) is very low $(-0.3)$ for the present model using the predicted IOP data. Similar peaks - primary peak around $0.500 \mu \mathrm{m}$ and secondary peak around $0.550 \mu \mathrm{m}$ - are also seen in the $L_{\mathrm{u}}$ spectrum. As the depth increases the secondary peak becomes more pronounced due to an increase in turbidity level. The deviation in $L_{\mathrm{u}}$ is very small for the present RT model as its predicted $L_{\mathrm{u}}$ spectra are well consistent with the measured $L_{\mathrm{u}}$ spectra, because of the inclusion of the effective bottom reflectance instead of the material reflectance.

\subsubsection{Moderately turbid waters}

Figure 12 shows the spectral variations of simulated and measured underwater light-field data for four discrete depths in moderately clear waters (with elevated chlorophyll in relatively deep waters as compared to the previous case) off Point Calimere (August 2012). At this location, the vertical profile of chlorophyll typically followed the Gaussian pattern, with 


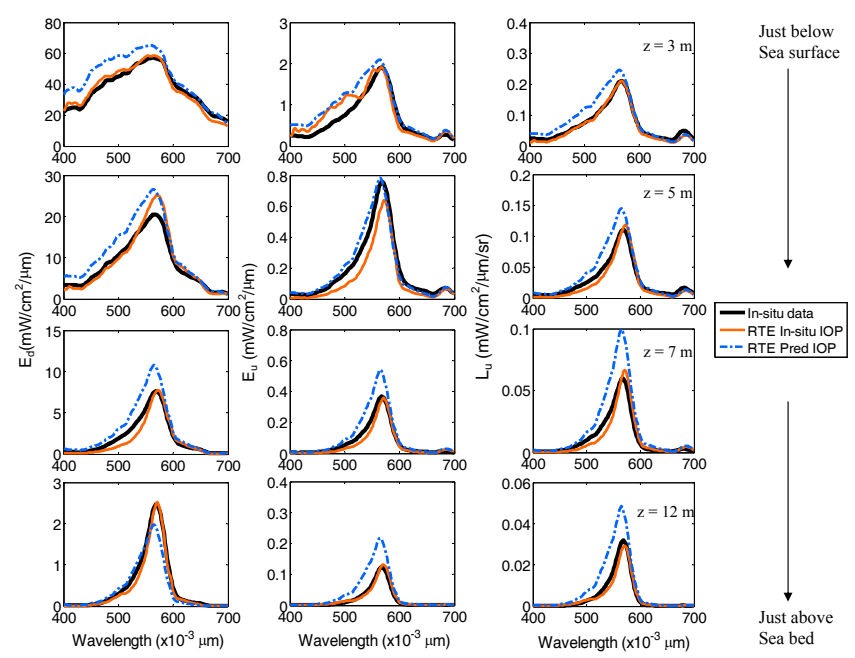

Figure 12. Spectral comparisons of the simulated and measured underwater light fields $\left(E_{\mathrm{d}}, E_{\mathrm{u}}\right.$ and $\left.L_{\mathrm{u}}\right)$ for four discrete depths in moderately turbid waters off Point Calimere (St-5). The black colour represents the measured data, orange colour represents results from the present RT model using in situ IOP data, and the blue colour represents results from the present RT model using the predicted IOPs from the remote-sensing reflectance data.

the surface chlorophyll $6.2 \mathrm{mg} \mathrm{m}^{-3}$ and maximum chlorophyll $18.5 \mathrm{mg} \mathrm{m}^{-3}$ at $7 \mathrm{~m}$. The range of suspended sediments varied from 10.9 to $15.3 \mathrm{~g} \mathrm{~m}^{-3}$. The solar zenith angle measured was $44.9^{\circ}$. Thus, the spectral pattern of $E_{\mathrm{d}}$ (first column) just below the surface resembles that of clear waters. As the depth increases, the pattern changes following the turbid water case with a major peak at $0.555 \mu \mathrm{m}$. The $E_{\mathrm{d}}$ spectra simulated from the present RT model using in situ IOP data have fairly good agreement with the measured $E_{\mathrm{d}}$. Since the predicted IOPs are low at the surface, the magnitude of the predicted $E_{\mathrm{d}}$ is relatively high when compared to the measured and simulated $E_{\mathrm{d}}$. The spectral pattern of $E_{\mathrm{u}}$ (second column) is slightly different for these waters as the primarily peak is located around $0.555 \mu \mathrm{m}$ and a secondary peak around $0.685 \mu \mathrm{m}$ due to the chlorophyll fluorescence. Similar features are also observed in the $L_{\mathrm{u}}$ spectra. The shape and magnitude of the $E_{\mathrm{u}}$ and $L_{\mathrm{u}}$ from the present RT model based on the in situ IOP data agrees well with measured data (with MRE values 0.1 and 0.04, respectively). By contrast, the $E_{\mathrm{u}}$ and $L_{\mathrm{u}}$ spectra generated from the present RT model using the predicted IOP data are improved although showing a slight overestimation in the green domain.

\subsubsection{Turbid coastal waters}

Figure 13 shows the spectral comparisons of simulated and measured underwater light fields $\left(E_{\mathrm{d}}, E_{\mathrm{u}}\right.$ and $\left.L_{\mathrm{u}}\right)$ for four discrete depths in turbid coastal waters off Point Calimere during August 2013. This station is in the vicinity of the coast with a depth of $6.3 \mathrm{~m}$, where the in situ measurements of ap-
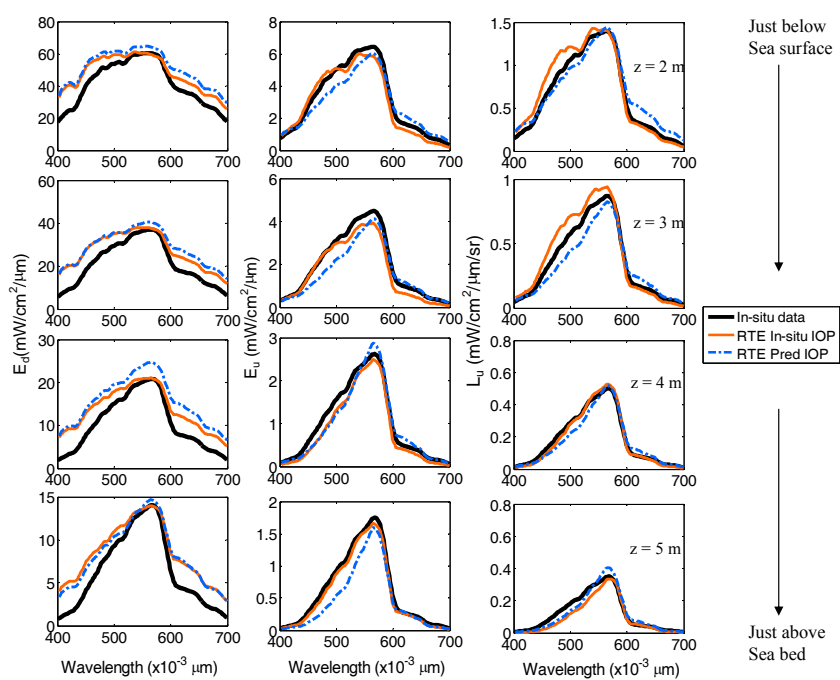

Figure 13. Spectral comparisons of the simulated and measured underwater light fields $\left(E_{\mathrm{d}}, E_{\mathrm{u}}\right.$ and $\left.L_{\mathrm{u}}\right)$ for four discrete depths in turbid coastal waters off Point Calimere (St-4). The black colour represents the measured data, orange colour represents results from the present RT model using in situ IOP data, and the blue colour represents results from the present RT model using the predicted IOPs from the remote-sensing reflectance data.

parent optical properties (AOPs), IOPs and other parameters were made when the solar zenith angle was $4.55^{\circ}$. At this station, the benthic resuspension and sediment transport noticeably increased the magnitude of the IOPs and turbidity. The measured $E_{\mathrm{d}}$ spectra (first column) show the maximum values at green wavelengths $(0.555 \mu \mathrm{m})$ and minimum values at blue and red wavelengths throughout the water column, which are the characteristic features of turbid waters. Note that the magnitude of $E_{\mathrm{d}}$ spectra from the present model using the in situ and predicted IOP data is closer to the measured $E_{\mathrm{d}}$ spectra, with low MRE values of 0.006 and 0.03 , respectively. The $E_{\mathrm{u}}$ and $L_{\mathrm{u}}$ spectra produced by the present RT model based on the in situ and predicted IOP data also match well with the measured $E_{\mathrm{u}}$ and $L_{\mathrm{u}}$ spectra (with relatively low MRE values of -0.06 to 0.1 and -0.1 to -0.09 , respectively). Better results associated with the present RT model are due to the modified boundary conditions and new phase function which varies along the depth.

\subsubsection{Phytoplankton-dominated harbour waters}

Figure 14 depicts the differences between simulated and measured underwater light fields in phytoplanktondominated harbour waters of Chennai. Since these waters were well mixed vertically, the vertical profiles of IOPs predicted by the respective models were considered continuous along the depth. The spectra of $E_{\mathrm{d}}, E_{\mathrm{u}}$ and $L_{\mathrm{u}}$ obtained from these waters appear slightly different from the previous cases because of a well-pronounced peak around $0.555 \mu \mathrm{m}$ and a fluorescence peak shifted from $0.685 \mu \mathrm{m}$ to $0.700 \mu \mathrm{m}$. Inter- 


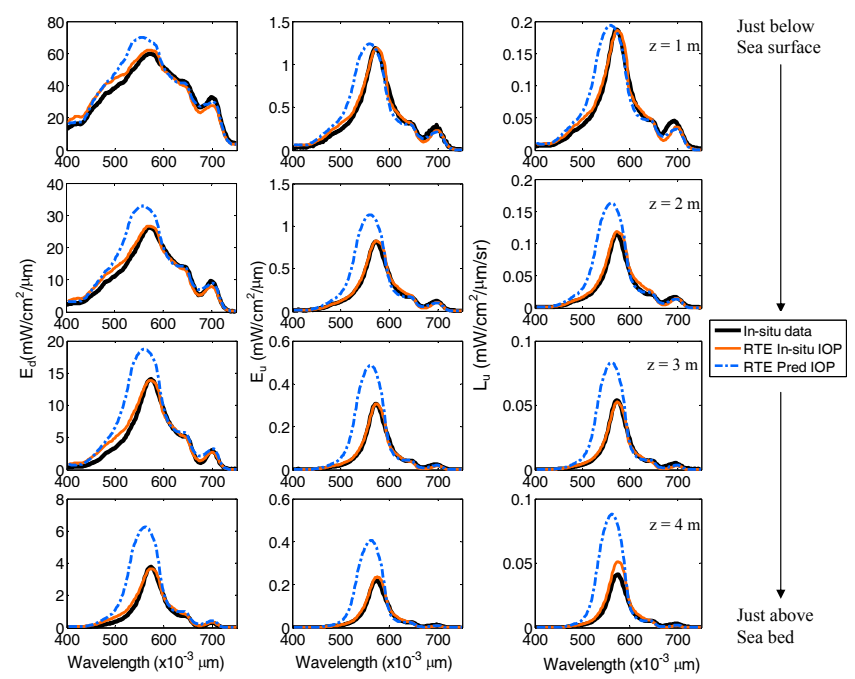

Figure 14. Spectral comparisons of the simulated and measured underwater light fields $\left(E_{\mathrm{d}}, E_{\mathrm{u}}\right.$ and $\left.L_{\mathrm{u}}\right)$ for four discrete depths in phytoplankton-dominated harbour waters off Chennai (St-7). The black colour represents the measured data, orange colour represents results from the present RT model using in situ IOP data, and the blue colour represents results from the present RT model using the predicted IOPs from the remote-sensing reflectance data.

estingly, the $E_{\mathrm{d}}, E_{\mathrm{u}}$ and $L_{\mathrm{u}}$ spectra of the present RT model from the in situ IOP data are well consistent with measured data across the entire visible wavelengths. As a result, its MRE values are reduced to 0.04 for $E_{\mathrm{d}}, 0.029$ for $E_{\mathrm{u}}$ and $L_{\mathrm{u}}$. Slight deviations are observed in the $E_{\mathrm{d}}, E_{\mathrm{u}}$ and $L_{\mathrm{u}}$ spectra generated by the present RT model, which could be attributed to errors associated with the predicted IOPs and the assumption of the vertically homogenous water column (i.e., constant IOPs along the depth). This would eventually increase the MRE values to 0.3 for $E_{\mathrm{d}}, 0.2$ for $E_{\mathrm{u}}$ and 0.26 for $L_{\mathrm{u}}$.

\subsubsection{Eutrophic waters}

The performance of the RT models is also examined in highly complex eutrophic waters, which exhibit much higher magnitudes in IOP spectra compared to other waters (Fig. 10). Figure 15 provides the spectral comparisons of simulated and measured underwater light fields from four different discrete stations (profile data not collected due to shallow water body). At these stations, both $\mathrm{Chl}$ and SS reached beyond 73 and $71 \mathrm{~g} \mathrm{~m}^{-3}$, respectively (in addition to high CDOM) ultimately reducing the magnitude of $E_{\mathrm{d}}$ (more at station St11) in the blue wavelength region and shifting the position of the red peak towards $0.715 \mu \mathrm{m}$ (by the combined effect of fluorescence and backscattering by the phytoplankton cells). Thus, the RT models failed to generate the measured $E_{\mathrm{d}}$ in the blue wavelength region although their results are reasonably good in the green and red regions. The mean MRE values (for $E_{\mathrm{d}}$ at $0.555 \mu \mathrm{m}$ ) are 0.003 and 0.016 for the present RT model using the predicted IOPs and in situ IOPs, respec-
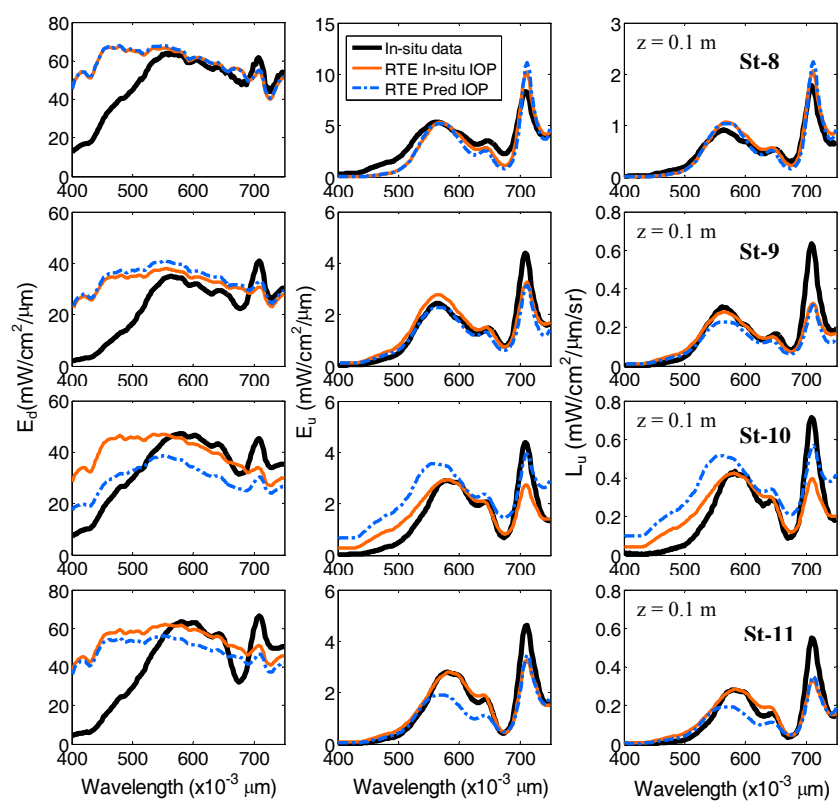

Figure 15. Spectral comparisons of the simulated and measured underwater light fields $\left(E_{\mathrm{d}}, E_{\mathrm{u}}\right.$ and $\left.L_{\mathrm{u}}\right)$ just below the surface in eutrophic waters off Chennai (St-8-11). The black colour represents the measured data, orange colour represents results from the present RT model using in situ IOP data, and the blue colour represents results from the present RT model using the predicted IOPs from the remote-sensing reflectance data.

tively. Interestingly, the present RT model based on the predicted and in situ IOP data gives accurate $E_{\mathrm{u}}$ and $L_{\mathrm{u}}$ in terms of magnitude and shape at all four stations. The shifted red peaks are also better captured by the present RT model due to the inclusion of the appropriate source function. The MRE values (at $0.555 \mu \mathrm{m}$ ) are 0.07 and -0.06 for the $E_{\mathrm{u}}$ and $L_{\mathrm{u}}$ (from the predicted IOP data) and 0.08 and -0.05 for the $E_{\mathrm{u}}$ and $L_{\mathrm{u}}$ (from the in situ IOP data). These results suggest that the present RT model can be used combined with remotesensing data to simulate the underwater light fields in a wide variety of waters.

\subsection{Depth variations in apparent optical properties}

This study is further extended for the calculation of the AOPs such as irradiance reflectance $R=E_{\mathrm{u}} / E_{\mathrm{d}}$, and subsurface remote-sensing reflectance $r_{\mathrm{rs}}=L_{\mathrm{u}} / E_{\mathrm{d}}$ from the underwater light-field parameters. Figure 16a shows the comparison of the depth profiles of the model and in situ irradiance reflectances $(R)$ at the wavelength of $0.555 \mu \mathrm{m}$ for moderately turbid water. The $R$ profiles increase (varying) with depth mainly due to the inhomogeneous water column conditions. Figure 16b shows the model and in situ subsurface remotesensing reflectance $r_{\text {rs }}$ profiles for moderately turbid water at the wavelength of $0.555 \mu \mathrm{m}$. Note that the $r_{\text {rs }}$ profiles are not constant along the depth. Since the AOPs mainly depend on the concentration of the constituents in the water column 

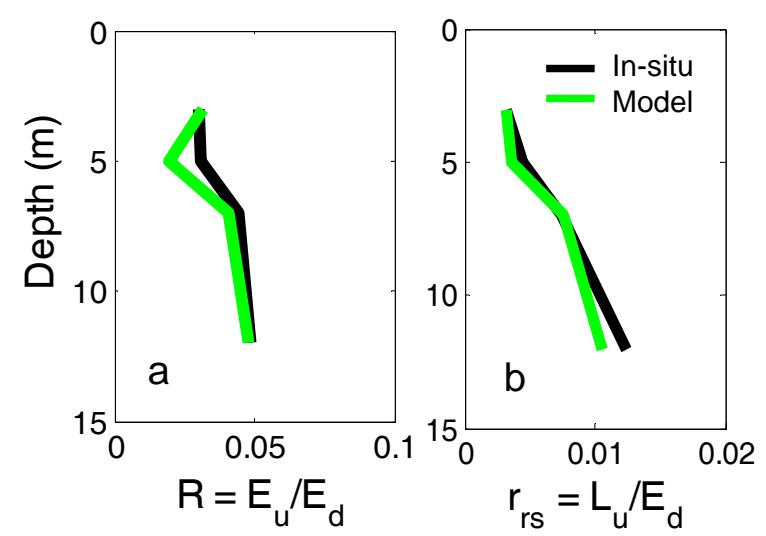

Figure 16. (a) Comparison of the measured and modelled reflectance $\left(R=E_{\mathrm{u}} / E_{\mathrm{d}}\right)$ at $0.555 \mu \mathrm{m}$ along the depth for moderately turbid water. (b) Comparison of the measured and modelled subsurface remote-sensing reflectance $\left(r_{\mathrm{rs}}=L_{\mathrm{u}} / E_{\mathrm{d}}\right)$ at $0.555 \mu \mathrm{m}$ along the depth for moderately turbid water. There is good agreement between the modelled and measured reflectance profiles at this station.

as well as light-field conditions, variations in the profiles of AOPs are expected in coastal waters (Pravin and Shanmugam, 2014). These results show that there is only a minimum likelihood for neither uniform nor constant AOPs $(R$, $\left.r_{\mathrm{rs}}\right)$ along the depth in such waters.

\section{Summary and conclusion}

Existing radiative transfer models to simulate the underwater light fields often lead to large uncertainties in turbid coastal and eutrophic waters. This could be due to the fact that some models treat the water column as homogenous (not considering the direct term), while others consider the water column as inhomogeneous (not considering the diffuse term). Assuming a constant phase function along the water column, a flat or oversimplified sea surface in a random manner, and considering the bottom material reflectance instead of the effective bottom reflectance (based on bottom slope and material reflectance) have already been reported to introduce large errors in the simulated underwater light fields (Sundarabalan et al., 2013). Thus, it is necessary to develop a reliable RT model to generate the underwater light-field parameters in a wide variety of waters.

To overcome the above issues, the proposed RT model can now handle more complex interactions of light with particulate matters with different surface and bottom boundary conditions. The direct and diffuse terms are included in this model to deal with the homogenous and inhomogeneous effects in the water column. The new sea surface boundary condition and the estimated sea surface transmittance have significant effects on the downwelling irradiance $\left(E_{\mathrm{d}}\right)$. As the sea surface slope increases, transmission through the airwater interface to the water column increases, but effects of the sea surface are most prominent when the sun is away from the nadir (Jin et al., 2006). The significance of the modified phase function is especially noticed in the simulated underwater light fields (Twardowski et al., 2001; Mobley et al., 2002; Freda and Piskozub, 2007; Sundarabalan et al., 2013). Since the sea bed is not uniform or flat, the inclusion of bottom morphology along with the material reflectance (effective bottom reflectance) in the bottom boundary shows better upwelling radiance $L_{\mathrm{u}}$ (Zaneveld and Boss, 2003). The bottom reflectance affects the entire water column, and is treated properly with IOPs along the depth (Lee et al., 1998). The source function based on the chlorophyll is included in the model and its effect is clearly seen in the simulated $E_{\mathrm{u}}$ and $L_{\mathrm{u}}$ with a florescence peak at $0.685 \mu \mathrm{m}$ (Gower et al., 2004). Finally, the calculated transmittance $T(z)$ is purely based on the IOPs (Haltrin and Kattawar, 1993; Haltrin, 1998a, b) and the reflectance $R(z)$ based on the IOPs and bottom effects (Lee et al., 1998). The results of the present RT model based on the in situ IOPs have good agreement with the measured underwater light-field parameters.

In the context of satellite remote sensing, the present RT model has been extended to predict the underwater light fields from the remotely sensed IOP profiles and its results have been validated using the measured underwater radiometric data and those simulated from the same RT model using the measured IOP profile data. The remotely sensed IOP profiles were derived from the new parameterisations developed by considering the different types of waters. These IOP profiles were determined based on the estimated $\mathrm{Chl}$ and SS. The chlorophyll profile was determined by the Gaussian distribution function (Lewis et al., 1983) and SS profile by the power-law function. The vertical structures of these estimated $\mathrm{Chl}$ and SS had good agreement with the measured profile data. It was found that the predicted underwater lightfield parameters $\left(E_{\mathrm{d}}, E_{\mathrm{u}}\right.$ and $\left.L_{\mathrm{u}}\right)$ from the present RT model using the Pred_IOPs are reasonably good when compared with the measured radiometric data as well as those obtained from the same RT model using the in situ IOP data in clear waters, turbid waters, phytoplankton-dominated waters and eutrophic waters. The differences between the predicted and measured $E_{\mathrm{d}}, E_{\mathrm{u}}$ and $L_{\mathrm{u}}$ may arise from the bio-optical parameterisations used to estimate the IOPs. Perhaps, the nonuniform trend of the chlorophyll pattern along the water column is also expected to cause these differences in the predicted $E_{\mathrm{d}}, E_{\mathrm{u}}$ and $L_{\mathrm{u}}$ by the present RT model. Nevertheless, this comprehensive study demonstrates that the present RT model is capable of dealing with homogenous and inhomogeneous water conditions and has the ability to generate more realistic underwater light-field parameters $\left(E_{\mathrm{d}}, E_{\mathrm{u}}\right.$ and $L_{\mathrm{u}}$ ) using the measured IOPs as well as those estimated from remote-sensing data. The present RT model is a viable alternative to existing models and has an important implication for remote sensing as well. 
Acknowledgements. This research was supported by INCOIS under the grant (OEC1314117INCOPSHA) of the SATCORE program. We thank D. Rajasekhar, The Head, Vessel Management Cell (VMC), and the Director of National Institute of Ocean Technology (NIOT) for providing Coastal Research Vessels to Indian Institute of Technology (IIT) Madras, Chennai, India for conducting various bio-optical measurements in coastal waters off Point Calimere and Chennai on the southeast coast of India. We are thankful to the scientists N. Ravi and K. Shashikumar of VMC for arranging the vessels to make the necessary measurements. We are thankful to the anonymous reviewers for their valuable comments to improve the quality of this manuscript.

Edited by: O. Zielinski

\section{References}

Ahn, Y. H.: Optical properties of biogenous and mineral particles present in the ocean. Application: inversion of reflectance, $\mathrm{PhD}$ Thesis, Paris-VI University, 1990.

Ahn, Y. H. and Shanmugam, P.: Detecting red tides from Satellite Ocean color observations in optically complex Northeast-Asia coastal waters, Remote Sens. Environ., 103, 419-437, 2006.

Antoine, D., André, J. M., and Morel, A.: Oceanic primary production: 2.Estimation at global scale from satellite (coastal zone colour scanner) chlorophyll, Global Biogeochem. Cy., 10, 5769, 1996.

Arrigo, K. R., Matrai, P. A., and van Dijken, G. L.: Primary productivity in the Arctic Ocean: Impacts of complex optical properties and subsurface chlorophyll maxima on large-scale estimates, J. Geophys. Res., 116, C11022, doi:10.1029/2011JC007273, 2011.

Babin, M., Stramski, D., Ferrari, G. M., Claustre, H., Bricaud, A., Obolensky, G., and Hoepffner, N.: Variations in the light absorption coefficients of phytoplankton, nonalgal particles, and dissolved organic matter in coastal waters around Europe, J. Geophys. Res., 108, C73211, doi:10.1029/2001JC000882, 2003.

Bricaud, A., Babin, M., Morel, A., and Claustre, H.: Variability in the chlorophyll-specific absorption coefficients of natural phytoplankton: analysis and parameterization, J. Geophys. Res., 100, 13321-13332, 1995.

Cherkasheva, A., Nöthig, E.-M., Bauerfeind, E., Melsheimer, C., and Bracher, A.: From the chlorophyll a in the surface layer to its vertical profile: a Greenland Sea relationship for satellite applications, Ocean Sci., 9, 431-445, doi:10.5194/os-9-431-2013, 2013.

Dmitriev, E. V., Khomenko, G., Chami, M., Sokolov, A. A., Churilova, T. Y., and Korotaev, G. K.: Parameterization of light absorption by components of seawater in optically complex coastal waters of the Crimea Peninsula (Black Sea), Appl. Opt., 48, 1249-1261, 2009.

Freda, W. and Piskozub, J.: Improved method of Fournier-Forand marine phase function parameterization, Opt. Exp., 20, 12763-8, 2007.

Gjerstad, K. I., Stamnes, J. J., Hamre, B., Lotsberg, J. K., Yan, B., and Stamnes, K.: Monte Carlo and Discrete-Ordinate Simulations of Irradiances in the Coupled Atmosphere-Ocean System, Appl. Opt., 42, 2609-2621, 2003.
Gokul, R. E., Shanmugam, P., and Sundarabalan, V. B.: Inversion models for deriving inherent optical properties and their vertical profiles in coastal waters, Cont. Shelf Res., 84, 120-138, 2014.

Gordon, H. R. and Morel, A.: Remote assessment of ocean colour for interpretation of satellite visible imagery: A review, Lecture notes on coastal and estuarine studies, Springer Verlag Heidelberg, Germany, 1983.

Gordon, H. R., Brown, O. B., and Jacobs, M. M.: Computed relationships between the inherent and apparent optical properties of a flat homogeneous ocean, Appl. Opt., 14, 417-427, 1975.

Gower, J. F. R., Brown, L., and Borstad, G. A.: Observation of chlorophyll fluorescence in west coast waters of Canada using the MODIS satellite sensor, Can. J. Remote Sens., 30, 17-25, 2004.

Haltrin, V. I.: Self-consistent approach to the solution of the light transfer problem for irradiances in marine waters with arbitrary turbidity, depth, and surface illumination. I. Case of absorption and elastic scattering, Appl. Opt., 37, 3773-3784, 1998a.

Haltrin, V. I.: Apparent optical properties of the sea illuminated by Sun and sky: case of the optically deep sea, Appl. Opt., 37, 83368340, 1998b.

Haltrin, V. I.: One-parameter two-term Henyey-Greenstein phase function for light scattering in seawater, Opt. Exp., 41, 1022-8, 2002.

Haltrin, V. I.: About nonlinear dependence of Remote Sensing and Diffuse reflection coefficients on Gordon's Parameter, Proceedings of the II International Conference "Current Problems in Optics of Natural Waters," ONW'2003, edited by: Levin, I. and Gilbert, G., St. Petersburg, Russia, 363-369, 2003.

Haltrin, V. I. and Kattawar, G. W.: Self-consistent solutions to the equation of transfer with elastic and inelastic scattering in oceanic optics, I. Model, Appl. Opt., 32, 5356-5367, 1993.

Hoepffner, N. and Sathyendranath, S.: Bio-optical Characteristics of coastal waters: Absorption spectra of phytoplankton and pigment distribution in the western North Atlantic, Limnol. Oceanogr., 37, 1660-1679, 1992.

Hollstein, A. and Fischer, J.: Radiative transfer solutions for coupled atmosphere ocean systems using the matrix operator technique, J. Quant. Spectrosc. Radiat. Transfer., 113, 536-548, 2012.

Huot, Y., Morel, A., Twardowski, M. S., Stramski, D., and Reynolds, R. A.: Particle optical backscattering along a chlorophyll gradient in the upper layer of the eastern South $\mathrm{Pa}$ cific Ocean, Biogeosciences, 5, 495-507, doi:10.5194/bg-5-4952008, 2008.

Jin, Z., Charlock, T. P., Rutledge, K., Stamnes, K., and Wang, Y.: Analytical solution of radiative transfer in the coupled atmosphere-ocean system with a rough surface, Appl. Opt., 45, 7443-7455, 2006.

Kirk, J. T. O.: Monte Carlo study of the nature of the underwater light field in, and the relationships between optical properties of, turbid yellow waters, Aust. J. Mar. Freshwater Res., 32, 517-532, 1981.

Lee, W. L. and Liou, K. N.: A coupled atmosphere-ocean radiative transfer system using the analytic Four-Stream approximation, J. Atmos. Sci., 64, 3681-3694, 2007.

Lee, Z. P., Carder, K. L., Mobley, C. D., Steward, R. G., and Patch, J. S.: Hyperspectral remote sensing for shallow waters. I. A semianalytical model, Appl. Opt., 37, 6329-6338, 1998. 
Lee, Z. P., Carder, K. L., Mobley, C. D., Steward, R. G., and Patch, J. S.: Hyperspectral remote sensing for shallow waters: 2. Deriving bottom depths and water properties by optimization, Appl. Opt., 38, 3831-3843, 1999.

Lewis, M. R., Cullen, J. J., and Platt, T.: Phytoplankton and thermal structure in the upper ocean: Consequences of non-uniformity in chlorophyll profile, J. Geophys. Res., 88, 2565-2570, 1983.

Martin, J., Tremblay, J. E., Gagnon, J., Tremblay, G., Lapoussiere, A., Jose, C., Poulin, M., Gosselin, M., Gratton, Y., and Michel, C.: Prevalence, structure and properties of subsurface chlorophyll maxima in Canadian Arctic waters, Mar. Ecol.-Prog. Ser., 412, 69-84, 2010.

Matsuoka, A., Hill, V., Huot, Y., Babin, M., and Bricaud, A.: Seasonal variability in the light absorption properties of western Arctic waters: Parameterization of the individual components of absorption for ocean colour applications, J. Geophys. Res., 116, C02007, doi:10.1029/2009JC005594, 2011.

Mobley, C. D.: Light and water: radiative transfer in natural waters, San Diego: Academic Press, Inc., 1994.

Mobley, C. D., Sundman, L. K., and Boss, E.: Phase function effects on oceanic light fields, Appl. Opt., 41, 1035-50, 2002.

Morel, A.: Optical modelling of the upper ocean in relation to its biogenous matter content (Case 1 waters), J. Geophys. Res., 93, 10749-10768, 1988

Morel, A.: Light and marine photosynthesis: a spectral model with geochemical and climatological implications, Prog. Oceanogr., 26, 263-306, 1991.

Morel, A. and Berthon, J. R.: Surface pigments, algal biomass profiles, and potential production of the euphotic layer: Relationships reinvestigated in view of remote-sensing application, Limnol. Oceanogr., 34, 1545-1562, 1989.

O'Reilly, J. E., Maritorena, S., Mitchell, B. G., Siegel, D. A., Carder, K. L., Garver, S. A., Kahru, M., and McClain, C.: Ocean colour algorithms for SeaWiFS, J. Geophys. Res., 103, $24937-$ 24953, 1998.

O'Reilly, J. E., Maritorena, S., O’Brien, M. C., Siegel, D. A., Toole, D., Menzies, D., Smith, R. C., Mueller, J. L., Mitchell, B. G., Kahru, M., Chavez, F. P., Strutton, P., Cota, G. F., Hooker, S. B., McClain, C. R., Carder, K. L., Karger, F. M., Harding, L., Magnuson, A., Phinney, D., Moore, G. F., Aiken, J., Arrigo, K. R., Letelier, R., and Culver, M.: Ocean Colour Chlorophyll a Algorithms for SeaWiFS, OC2 and OC4: Version 4, NASA Technical Memorandum, 11, 9-23, 2000.

Pierson, W. J. and Moskowitz, L.: Proposed spectral form for fully developed wind seas based on similarity theory of S. A. Kitaigorodskii, J. Geophys. Res., 69, 5181-5190, 1964.

Pegau, W. S., Gray, D., and Zaneveld, J. R. V.: Absorption and attenuation of visible and near-infrared light in water: dependence on temperature and salinity, Appl. Opt., 36, 6035-6046, 1997.

Platt, T. and Sathyendranath, S.: Oceanic Primary Production: Estimation by Remote Sensing at Local and Regional Scales, Science, 241, 1613-1620, 1988.

Pope, R. M. and Fry, E. S.: Absorption spectrum (380-700 nm) of pure water. II. Integrating cavity measurements, Appl. Opt., 36, 8710-8723, 1997.

Pravin, J. D. and Shanmugam, P.: A new model for the subsurface irradiance reflectance in clear and turbid waters, Opt. Exp., 22, 9548-9566, 2014.
Prieur, L. and Sathyendranath, S.: An optical classification of coastal and oceanic waters based on the specific spectral absorption curves of phytoplankton pigments, dissolved organic matter, and other particulate materials, Limnol. Oceanogr., 26, 671-689, 1981.

Ramakrishnan, R., Rajawat, A. S., and Chauhan, O. S.: Suspended sediment concentration profiles from synoptic satellite observations, IEEE J. Sel. Topics Appl. Earth Observ. Remote Sens., 6, 2051-2057, 2013.

Sathyendranath, S. and Platt, T.: Remote sensing of ocean chlorophyll: consequence of non-uniform pigment profile, Appl. Opt., 28, 490-495, 1988.

Shanmugam, P.: A new bio-optical algorithm for the remote sensing of algal blooms in complex ocean waters, J. Geophys. Res., 116, C04016, doi:10.1029/2010JC006796, 2011a.

Shanmugam, P.: New models for retrieving and partitioning coloured dissolved organic matter in the global oceans. Implications for remote sensing, Remote Sens. Environ., 115, 15011521, 2011b.

Shanmugam, P., Ahn, Y. H., Ryu, J. H., and Sundarabalan, V. B.: An evaluation of inversion models for retrieval of inherent optical properties from ocean colour in coastal and open sea waters around Korea, J. Oceanogr., 66, 815-830, 2010.

Shanmugam, P., Sundarabalan, V. B., Ahn, Y. H., and Ryu, J. H. A.: New Inversion Model to Retrieve the Particulate Backscattering in Coastal/Ocean Waters, IEEE Trans. Geosci. Remote Sens., 49, 2463-74, 2011.

Smith, R. C.: Ocean colour for the estimation of Global marine primary productivity, Workshop on the Global Ocean Flux study, Woods Hole, Masschusetts, 103-110, 1984

Smith, R. C. and Baker, K. S.: Optical properties of the clearest natural waters (200-800 nm), Appl. Opt., 20, 177-184, 1981.

Stamnes, K., Tsay, S., Wiscombe, W., and Jayaweera, K.: Numerically stable algorithm for discrete-ordinate-method radiative transfer in multiple scattering and emitting layered media, Appl. Opt., 27, 2502-2509, 1988.

Stramska, M. and Stramski, D.: Effects of a non-uniform vertical profile of chlorophyll concentration on remote-sensing reflectance of the ocean, Appl. Opt., 44, 1735-1747, 2005.

Stramski, D., Bricaud, A., and Morel, A.: Modelling the inherent optical properties of the ocean based on the detailed composition of the planktonic community, Appl. Opt., 40, 2929-2945, 2001.

Sundarabalan, V. B., Shanmugam, P., and Manjusha, S. S.: Radiative transfer modelling of upwelling lightfield in coastal waters, J. Quant. Spectrosc. Radiat. Transfer., 121, 30-44, 2013.

Twardowski, M. S., Boss, E., Macdonald, J. B., Pegau, W. S., Barnard, A. H., and Zaneveld, J. R. V.: A model for estimating bulk refractive index from the optical backscattering ratio and the implications for understanding particle composition in case I and case II waters, J. Geophys. Res., 106, 14129-14142, 2001.

Uitz, J., Claustre, H., Morel, A., and Hooker, S. B.: Vertical distribution of phytoplankton communities in open ocean: An assessment based on surface chlorophyll, J. Geophys. Res., 111, C08006, doi:10.1029/2005JC003207, 2006.

Wang, Y., Liu, D., Song, K., Du, J., Wang, Z., Zhang, B., Tang, X., Lei, X., and Wu, Y.: Characterization of Water Constituents Spectra Absorption in Chagan Lake of Jilin Province, Northeast China, Chin. Geogra. Sci., 21, 34-345, 2011. 
Wozniak, S. B. and Stramski, D.: Modelling the optical properties of mineral particles suspended in seawater and their influence on ocean reflectance and chlorophyll estimation from remote sensing algorithms, Appl. Opt., 43, 3489-3503, 2004.

Zaneveld, J. R. V. and Boss, E.: The influence of bottom morphology on reflectance: theory and two-dimensional geometry model, Limnol. Oceanogr., 48, 374-379, 2003.
Zhang, Y., Liu, M., Qin, B., Woerd, H. J., Li, J., and Li, Y.: Modelling remote-sensing reflectance and retrieving Chlorophyll-a concentration in extremely turbid case-2 waters (lake Taihu, China), IEEE Trans. Geosci. Remote Sens., 47, 1937-1948, 2009. 